\title{
Bank Resolution and the Structure of Global Banks
}

\author{
Patrick Bolton \\ Columbia University \\ Martin Oehmke \\ London School of Economics
}

\begin{abstract}
We study the resolution of global banks by national regulators. Single-point-of-entry (SPOE) resolution, where loss-absorbing capital is shared across jurisdictions, is efficient but faces implementation constraints. First, when expected transfers across jurisdictions are too asymmetric, national regulators fail to set up SPOE resolution ex ante. Second, when required ex post transfers are too large, national regulators ring-fence assets instead of cooperating in SPOE resolution. In this case, a multiple-point-of-entry (MPOE) resolution, where loss-absorbing capital is preassigned, is more robust. Our analysis highlights a fundamental link between efficient bank resolution, the operational structures, risks, and incentives of global banks. (JEL G21, G28, G33)
\end{abstract}

Received July 24, 2017; editorial decision August 20, 2018 by Editor Itay Goldstein. Authors have furnished an Internet Appendix, which is available on the Oxford University Press Web site next to the link to the final published paper online.

One of the main unresolved issues in financial regulation is how to deal with global banks that are too big to fail. The collapse of Lehman Brothers demonstrated the immense costs of the failure of such an institution, with devastating repercussions for the financial system and the broader economy.

For comments and suggestions, we thank three anonymous referees, Kartik Anand, David Arsenau, Arnaud Boot, Elena Carletti, Douglas Diamond, Darrell Duffie, Wilson Ervin, Itay Goldstein (the editor), Charles Goodhart, Gary Gorton, Martin Hellwig, Randy Kroszner, Frédéric Malherbe, George Pennacchi, Caspar Siegert, Martin Summer, Paul Tucker, and Ansgar Walther. We also thank seminar and conference participants at LSE, INSEAD, the London Financial Intermediation Theory Network, Carnegie Mellon University, Yale SOM, Washington University in St. Louis, Imperial College, Bocconi, Lausanne, Cambridge, Princeton, Arizona State, the MPI for Research on Collective Goods, Warwick, Oxford, the 2016 Bundesbank Spring Conference, the 5th ITAM Conference, the 2016 FIRS meetings, the 2016 SAFE Conference on Regulating Financial Markets, the 2016 ESSFM meetings in Gerzensee, the 2016 FRIC conference, University of Amsterdam, the Dutch National Bank, Queen Mary University, the 2016 Colorado Finance Summit, the 2017 AFA, DIW Berlin, the Bank of England, NYU Stern, the Duke/UNC Corporate Finance Conference, the Bank of Italy, Stanford GSB, the 2017 Bank of Portugal Conference, the Single Resolution Board, the French Prudential Supervision and Resolution Authority (ACPR), and the Federal Reserve Bank of New York. The authors thank Ran Shi for research assistance. Oehmke gratefully acknowledges financial support from the Paul Woolley Centre and the European Research Council [starting grant 714567]. Supplementary data can be found on The Review of Financial Studies Web site. Send correspondence to Martin Oehmke, Department of Finance, London School of Economics, Houghton Street, London WC2A 2AE, UK. E-mail: m.oehmke@lse.ac.uk.

(c) The Author(s) 2018. Published by Oxford University Press.

This is an Open Access article distributed under the terms of the Creative Commons Attribution License (http://creativecommons.org/licenses/by/4.0/), which permits unrestricted reuse, distribution, and reproduction in any medium, provided the original work is properly cited. 
Yet bailouts and public guarantees that would prevent such failures also involve costs, creating moral hazard and incentives for financial institutions to grow ever larger and more complex. The proposed solution to this dilemma is bank resolution. Both Title II of the Dodd-Frank Act in the United States and the Bank Recovery and Resolution Directive (BRRD) in the European Union call for novel but, as of yet, untested resolution mechanisms for global systemically important banks (G-SIBs). These proposals aim to end too big to fail by providing a credible way to resolve and recapitalize failing G-SIBs with minimal disruption and without taxpayer support. ${ }^{1}$

In this paper we analyze the key trade-offs that arise in cross-border resolution of global banks, taking into account the political constraints faced by national regulators. We show that, although conducting a single, global resolution for an entire multinational bank (a "single-point-of-entry" resolution) is efficient in principle, it is not always compatible with the interests of national regulatory authorities, who may prefer to ring-fence their national banking industries. In that situation, conducting (and planning for) separate resolutions in different jurisdictions (a "multiple-point-of-entry" resolution) is more efficient. Overall, our model highlights that credible G-SIB resolution is not "one size fits all." Rather, resolution should take into account a bank's risk structure and operational complementarities across different jurisdictions.

The challenge in designing resolution mechanisms for G-SIBs is to adapt existing resolution procedures for smaller (i.e., national or regional) banks to the resolution of much larger banks that operate across multiple jurisdictions. Indeed, resolution under Title II of the Dodd-Frank Act is partially modeled after the FDIC receivership procedure used to resolve small- and mediumsized banks. A central element of FDIC resolution is purchase and assumption (P\&A), by which a healthy bank purchases assets and assumes liabilities of the troubled bank. For a modest-sized bank, such a resolution and sale can usually be completed over a weekend, such that operations can resume on the following Monday. In contrast, for a failing G-SIB such a swift transfer of assets and liabilities over the course of a weekend is typically not feasible. GSIBs are simply too large, and their balance sheets far too complex for a quick $\mathrm{P} \& \mathrm{~A}$ to be an option. In addition, the resolution of G-SIBs has an inherent cross-jurisdictional component that is not an issue when the FDIC resolves a domestic bank.

The proposed solution to this challenge is to perform a G-SIB resolution through a liability-side restructuring of the failing institution (see FDIC and Bank of England 2012; Financial Stability Board 2014). Specifically, troubled operating subsidiaries of a G-SIB are recapitalized by writing down long-term liabilities known as TLAC ("total loss-absorbing capital" in the form of equity and subordinated long-term debt) issued by a nonoperating holding company.

1 For an overview of the key features of the resolution proposals in the United States and in the European Union, see Philippon and Salord (2017). 
Multiple point of entry (MPOE):

Loss-absorbing capital in each jurisdiction

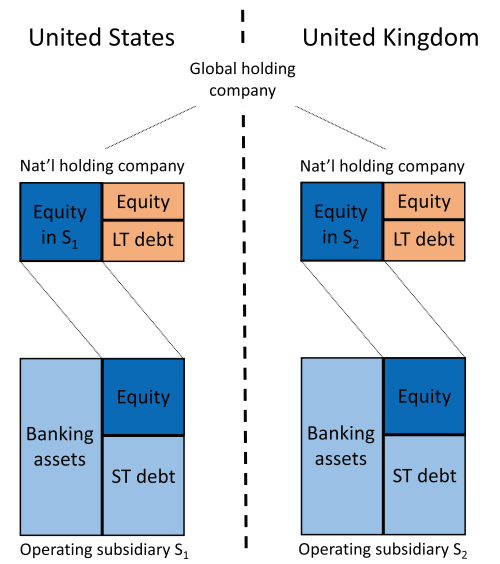

Single point of entry (SPOE):

Loss-absorbing capital shared

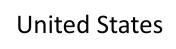

Global holding company

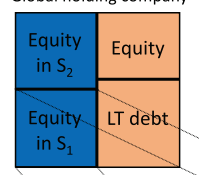

United Kingdom

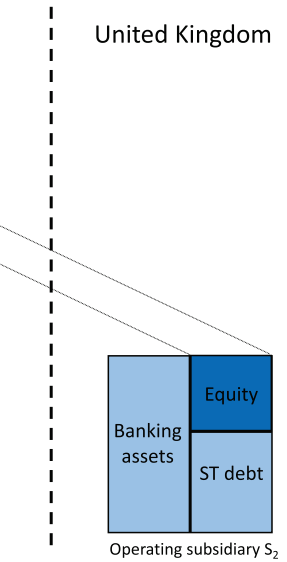

Figure 1

MPOE and SPOE resolution

The figure illustrates multiple-point-of-entry (MPOE) and single-point-of-entry (SPOE) resolution. Under MPOE (left panel), loss-absorbing capital, in the form of outside equity and long-term debt, is separately issued by national holding companies in each jurisdiction. In resolution the global bank is split up, and national regulators perform separate resolutions, drawing on the loss-absorbing capital available in each jurisdiction. Consequently, loss-absorbing capital is not shared, and no cross-jurisdictional transfers occur during resolution. Under SPOE (right panel), loss-absorbing capital is issued by a global holding company and is therefore shared across jurisdictions. Because the bank is resolved as a whole, in contrast to MPOE, SPOE allows for cross-jurisdictional transfers during resolution.

Crucially, recapitalization via a nonoperating holding company allows the G-SIB's operating subsidiaries to remain open for business as usual during the resolution and protects the operating subsidiaries' runnable short-term liabilities, thereby preventing destabilizing runs on the G-SIB's operations.

Policy makers have debated two alternative resolution models, which are illustrated in Figure 1: (1) multiple-point-of-entry (MPOE) resolution, under which the global bank is split along jurisdictional lines and national regulators perform a separate resolution, drawing on loss-absorbing capital and liquidity separately held by national holding companies in each jurisdiction and (2) single-point-of-entry (SPOE) resolution, under which a global bank is resolved as a whole through a single global holding company that holds banking subsidiaries in multiple jurisdictions. The key difference is that, under MPOE, loss-absorbing capital is not shared across jurisdictions and no cross-jurisdictional transfers occur, whereas SPOE allows for the sharing of loss-absorbing capital and cross-jurisdictional transfers during resolution.

The contribution of our paper is to characterize the main trade-offs between MPOE and SPOE resolution in the context of a simple model of global banks and national regulators. We first show that bank resolution that is exclusively conducted through an intervention on the liability side-by imposing losses on equity or writing down debt issued by the financial institution's holding 
company - has to go hand in hand with a regulatory requirement for holding companies to issue a sufficient amount of equity or long-term debt so as to guarantee sufficient loss-absorbing capacity. In our model, asymmetric information about long-term cash flows makes equity and long-term debt expensive relative to short-term debt. Therefore, absent a requirement to issue long-term loss-absorbing securities, financial institutions may choose to rely excessively on short-term debt as a source of funding. Because runnable shortterm debt cannot credibly be written down, an orderly resolution then becomes impossible. Like in the fall of 2008, this would leave a disorderly liquidation via a bank run or a tax-funded bailout as the only remaining options.

We then show that, for global financial institutions that operate in multiple jurisdictions, SPOE is the efficient resolution mechanism in a benchmark setting in which regulators maximize joint surplus and can commit to cooperating in the middle of a crisis, thereby emulating the actions of a benevolent supranational regulator. Because SPOE resolution allows regulators to transfer resources between operating subsidiaries in different jurisdictions, a successful SPOE resolution regime can be achieved with a lower amount of required loss-absorbing capital than would be possible under separate national MPOE resolution schemes. As a result, for the same level of risk acceptable to regulators, SPOE resolution allows global financial institutions to provide more socially beneficial banking services than would be possible under MPOE resolution. Moreover, because the bank is resolved as a whole, efficiency gains from global banking are preserved.

However, under the regulatory status quo-in which global financial institutions are resolved by national regulators-it may be difficult to realize the benefits of a global SPOE resolution. First, whenever expected crossjurisdictional transfers are sufficiently asymmetric, the national regulator that makes the larger expected transfer has an incentive to opt out of a globally efficient cross-jurisdiction SPOE resolution and to set up a national resolution scheme instead. From an ex ante perspective, the creation of an efficient SPOE resolution regime is therefore feasible only if the expected cross-jurisdictional transfers are sufficiently symmetric.

Second, SPOE resolution may not be implementable ex post, even when agreed upon ex ante. When the cross-jurisdictional transfer required for a successful SPOE resolution is too large, regulators may prefer to ring-fence assets in their own jurisdiction, thereby preventing the required transfers. The planned SPOE resolution breaks down, leading to a disorderly liquidation or a tax-funded bailout. We show that the possibility of such an ex post breakdown of a planned SPOE resolution depends on the risk profile and operational structure of the financial institution at hand. In particular, incentive-compatible SPOE resolution requires operational complementarities across national banking operations, such as those arising from joint cash management or other shared services. The prospect of losing these complementarities incentivizes regulators not to ring-fence assets ex post. 
When SPOE resolution is not ex post incentive compatible, MPOE resolution, where loss-absorbing capital is held by national holding companies in each jurisdiction, can still support a successful resolution. MPOE resolution eliminates some of the diversification benefits that would be achievable under SPOE, but the absence of cross-jurisdictional transfers implies that MPOE is not subject to ex post incentive compatibility constraints. Accordingly, ex post incentive compatibility generates a link between bank structure and the appropriate resolution model. In particular, for global banks with more decentralized operations and larger required transfers during resolution, a more robust MPOE resolution model is appropriate. More generally, we show that the constrained optimal resolution mechanism in this situation follows a hybrid approach, where an appropriate amount of loss-absorbing capital is preassigned to particular jurisdictions, thereby restoring incentive compatibility while preserving some benefits of resource sharing in resolution. These results shed light on recent proposals for the prepositioning of "internal TLAC" within G-SIBs.

Finally, we investigate how the choice of resolution regime affects the incentives of local operating subsidiaries. We first show that, under SPOE resolution, the local operating subsidiaries only exert effort to produce cash flows that generate diversification benefits across jurisdictions if resolution is sufficiently unlikely. Effectively, cross-jurisdictional transfers result in a statecontingent debt overhang problem that reduces incentives to generate cash flows that generate diversification benefits. When incentives to generate these cash flows cannot be sustained in equilibrium, SPOE resolution loses some of its appeal and an MPOE approach can become more appropriate. We then provide a more general comparison of incentives under MPOE and SPOE. Here we show that the operating subsidiaries' incentives to produce the cash flows depend on the net effect of two forces. On the one hand, SPOE dampens incentives relative to MPOE because cash flows generated in one jurisdiction can be transferred to plug a hole in the other jurisdiction. On the other hand, because it economizes on loss-absorbing capital, SPOE resolution can allow the bank to offer larger (inside) equity stakes to affiliate managers, providing stronger incentives to generate cash flow. In addition, we show that TLAC composition affects incentives under both SPOE and MPOE. Whereas under SPOE a larger fraction of TLAC in the form of debt always improves incentives, under MPOE it is possible that incentives are maximized under all-equity TLAC. For the hotly debated issue of TLAC composition, our model therefore indicates that the right debt-equity mix depends on the adopted resolution model.

Despite the ongoing policy debate (see, in particular, Tucker 2014a,b), almost no formal economic analysis of the trade-offs between MPOE and SPOE resolution exists. One exception is Faia and Weder di Mauro (2016), who analyze how the losses that regulators impose on domestic and foreign bondholders under MPOE and SPOE resolution depend on a bank's mix of domestic and foreign assets and liabilities. Another exception is Ervin (2017), 
who provides a quantitative analysis of the loss of diversification and greater risk of failure, for the same amount of aggregate capital, that results from the elimination of a flexible central capital reserve under MPOE resolution. Several related papers investigate other aspects of bank resolution: Jackson and Skeel (2012) and Skeel (2014) compare resolution under Dodd-Frank with the alternative of restructuring a failed G-SIB through bankruptcy; Duffie (2014) discusses the resolution of failing central counterparties, which, like G-SIBs, are likely to be too big to fail; Walther and White (2017) provide a model of bank resolution in which regulators may be too soft during a resolution, for fear of spooking market participants; and Beck, Todorov, and Wagner (2013) analyze how incentives for national regulators to intervene depend on foreign asset holdings and equity ownership of the bank in question. Colliard and Gromb (2018) study how bank resolution affects banks' incentives to privately restructure outside of resolution, whereas Segura and Vicente (2018) analyze the design of a public backstop in a banking union. The cross-jurisdictional focus of our analysis relates to the literature on transnational bankruptcy for nonfinancial institutions. In particular, consistent with our analysis, Bebchuk and Guzman (1999) argue that the territoriality rule in bankruptcy law is inefficient and dominated by the universalism rule. Nevertheless, political economy considerations often lead national bankruptcy courts to inefficiently implement national bankruptcy proceedings.

A number of papers explore the supervision (but not resolution) of multinational banks. Dell'Ariccia and Marquez (2006) characterize the tradeoff between internalizing externalities and loss of flexibility inherent in regulatory unions. They show that supranational capital regulation is less likely to emerge when national regulators differ in the extent to which they are captured by their domestic financial industries. In a similar spirit, Beck and Wagner (2016) find that the benefits from supranational regulation increase with cross-border externalities but decrease with country heterogeneity. Carletti, Dell'Ariccia, and Marquez (2015) show that some of the benefits of centralized supervision may be offset by inferior information collection by national regulators. Calzolari and Lóránth (2011), Colliard (2017), and Calzolari, Colliard, and Lóránth (forthcoming) study the incentives of regulators to monitor multinational banks and investigate how national or supranational supervision interacts with banks' legal structures and their decisions to expand abroad. Lóránth and Morrison (2007) consider a model of a multinational bank that has excess risk-taking incentives driven by insured deposits. They argue that bank shareholders prefer to set up foreign subsidiaries rather than bank branches because this organizational structure gives rise to a less diversified portfolio, which is more attractive to risk-seeking shareholders. Our analysis complements these studies by exploring the supranational aspects of bank resolution (as opposed to supervision). More generally, the idea of resolving banks and preventing bank runs by imposing losses on long-term creditors is related to recapitalization via contingent convertible securities (CoCos). For 
a survey of this literature, see Flannery (2014). Finally, whereas our analysis focuses on loss-absorbing capital on the liability side, Diamond and Kashyap (2016) explore the role of liquidity requirements on the asset side in preventing bank runs.

\section{Model}

We consider a model with three dates, $t=0,1,2$. The model features two types of players: (1) a multinational financial institution that operates in two jurisdictions and (2) two national regulators with resolution authority in their respective jurisdictions.

\subsection{The global bank}

A multinational financial institution operates two subsidiaries, each located in a different jurisdiction, $i=1,2$, say, the United States and the United Kingdom. ${ }^{2}$ Each operating subsidiary runs its own stylized banking operation, which we model as follows. At date 0 , each subsidiary raises a fixed amount $F$, which it invests in the provision of banking services. This investment is funded through a combination of short-term debt with face value $R_{1}$ due at date 1 (e.g., demand deposits, wholesale funding, certificates of deposit, short-term commercial paper), long-term subordinated debt with face value $R_{L T}$ due at date 2, and an outside equity stake $\alpha_{0}$ that is issued at date 0 . We assume that outside equity and long-term subordinated debt are issued by a holding company that owns the equity of the operating subsidiaries, as illustrated in Figure 1. Under this arrangement, operating subsidiary losses are automatically passed up to the holding company and absorbed by the holders of the TLAC securities (equity and long-term) debt issued by the holding company. Issuing lossabsorbing securities at the holding company level implies that these securities are structurally subordinated to the short-term debt claims that are issued by the operating subsidiaries. During a resolution, when time is of the essence, it is then straightforward to determine which claims will absorb losses, allowing for a speedy resolution. ${ }^{3}$ Moreover, issuing subordinated claims at the holding company level potentially allows for the sharing across jurisdictions of the loss-absorbing capacity provided by these securities.

To capture the benefits of banking activity and liquidity provision, we assume that each dollar of safe short-term debt issued by the bank yields a liquidity benefit $\gamma>0$ over and above the cash flows backing this claim. This assumption

2 In line with current resolution proposals, we focus our analysis on subsidiary structures. In Section 6.4 , we provide a discussion of the choice between branch and subsidiary structures in the context of bank resolution. Moreover, in practice, global banks usually have multiple operating subsidiaries within the same jurisdiction. We abstract from this consideration to focus on the international aspect of resolving global financial institutions.

3 In addition, to guarantee structural subordination, the holding company is generally required not to have any operations of its own (i.e., it is a nonoperating or "clean" holding company). 
captures, in reduced form, the benefits from maturity transformation performed by banks ${ }^{4}$ and the nonpecuniary liquidity services obtained from safe moneylike securities issued by banks. 5

Banking operations yield cash flows at dates 1 and 2. Two aggregate states are possible at date 1 . With probability $p_{1}$, the high aggregate state occurs, and both operating subsidiaries receive a high cash flow $C_{1}^{H}$. With probability $1-p_{1}$, the low aggregate state is realized, and both subsidiaries receive the low cash flow $0<C_{1}^{L}<C_{1}^{H}$. The aggregate state captures undiversifiable cash-flow risk that both operating subsidiaries are exposed to. For simplicity, we assume that the two operating subsidiaries have the same exposure to the aggregate shock.

In addition to this aggregate cash-flow risk, the operating subsidiaries are also exposed to diversifiable cash-flow risk at date 1 . Specifically, we assume that one of the two banking subsidiaries receives an additional cash flow of $\Delta>0$. This additional cash flow $\Delta$ is received by the operating subsidiary in jurisdiction $i$ with probability $\theta_{i}$, where $\theta_{1}+\theta_{2}=1$. Therefore, even though $\Delta$ is risk-free from a global perspective, it is a risky cash flow from the perspective of each individual operating subsidiary. ${ }^{6}$ We assume that the bank cannot easily hedge this risk. ${ }^{7}$ We assume that $C_{1}^{H}$ is sufficiently high that both operating subsidiaries can meet their short-term liabilities in the high cash-flow state, regardless of who receives $\Delta$. When $C_{1}^{L}$ is realized, on the other hand, the banking subsidiaries will not necessarily have sufficient funds to repay or roll over their short-term debt obligation $R_{1}$, thereby creating a need for bank resolution.

The cash flow at date 2 summarizes the continuation (or franchise) value of the two subsidiaries. We assume that with probability $p_{2}^{i}$ the operating

4 See Diamond and Dybvig (1983), Calomiris and Kahn (1991), and Diamond and Rajan (2001).

5 When safe short-term debt issued by the bank functions as money (e.g., deposits), the interest paid by the bank on these claims is lower than the market interest rate, reflecting the demand for money, like in Klein (1974) (see also Li 2017; Donaldson and Piacentino 2018). As pointed out by Nagel (2016), the available evidence suggests that demand deposits pay between one-third and half of the market interest rate. For claims that are close money substitutes (e.g., repos, short-term commercial paper), the interest paid by the bank is reduced by the premium on near-money assets. Krishnamurthy and Vissing-Jorgensen (2012) and Greenwood, Hanson, and Stein (2015) document a premium for near-money assets of around 40-70 bps. Sunderam (2014) and Krishnamurthy and Vissing-Jorgensen (2015) show that the financial sector reacts to capture this premium by issuing safe short-term debt.

6 This cash-flow structure captures the diversification benefits arising from operations in multiple jurisdictions. Empirically, these diversification benefits can be estimated from the correlation of earnings across jurisdictions. We have chosen the simplest possible representation of these benefits, where $\Delta$ is of known size and always materializes. It is relatively straightforward to extend our framework to allow for random $\Delta$ or for uncertainty about whether $\Delta$ is received at all. We discuss these extensions in more detail in the Online Appendix. They do not lead to major changes in the economic insights of our model.

7 In the simplest interpretation, this assumption captures the fact that there may simply be no financial instrument available for hedging this risk. Even when a hedging instrument is available, it is realistic to assume that this does not allow the bank to hedge this risk in the resolution state, where private contracts can be overruled by resolution authorities. In particular, resolution authorities can generally prevent a transfer of resources from one jurisdiction to the other by ring-fencing assets, as will be discussed in more detail below. 
subsidiary in jurisdiction $i$ receives a positive continuation value of $C_{2}=V{ }^{8}$ With probability $1-p_{2}^{i}$, the continuation value is zero $\left(C_{2}=0\right)$. The probability $p_{2}^{i}$ of receiving the continuation value $V$ is private information of the bank, both at date 0 and at date 1 . For simplicity, we assume that $p_{2}^{i} \in\{0,1\}$ and that uninformed investors' belief that $p_{2}^{i}=1$ is given by $\bar{p}_{2}$ (again, both at date 0 and at date 1). Like in Bolton and Freixas $(2000,2006)$, the assumption that $p_{2}^{i}$ is private information implies that it is expensive for a bank with high $p_{2}^{i}$ to raise funds against the continuation cash flows at date 2 . This is why long-term debt and equity are expensive funding sources relative to short-term debt.

When an operating subsidiary is unable to repay or roll over its short-term debt at date 1, short-term creditors run on the bank's short-term liabilities and the bank is liquidated at date $1 .{ }^{9}$ We assume that liquidation is inefficient, in the sense that the liquidation payoff $L$ is strictly smaller than the market's expected value of the banking franchise, $L<\bar{p}_{2} V$.

Finally, we model the (potential) benefits arising from global banking activity by assuming that the continuation value $V$ is contingent on the two subsidiaries continuing to operate within the same global bank after date 1 . If the two subsidiaries are separated at date 1 (e.g., because national regulators invoke separate resolution procedures or when one of the two subsidiaries is liquidated), this reduces the continuation value to $\lambda V$, where $\lambda \leq 1$. This assumption captures the loss of economies of scale and scope that results from the breakup of the global bank. For example, separation of the subsidiaries eliminates efficiency gains arising from joint cash management, common IT systems, and other shared services. ${ }^{10}$ If the operating subsidiaries want to prevent the reduction in continuation value that results from splitting up the global bank at date 1 , they can do so by setting up redundant systems ex ante (e.g., by making sure that each operating subsidiary has its own independent cash management system). Redundant systems require a higher setup cost $\widetilde{F}>F$. However, when a split-up of the global bank is sufficiently likely, it may be more efficient to incur this higher setup cost than lose economies of scope ex post. A key implication of this assumption is that it generates an interaction between the resolution model and the global bank's operational

8 Without much loss of generality and to reduce the number of subcases to consider, we assume that the date-2 continuation values of the operating subsidiaries in each jurisdiction $i$ are identical, $V_{i}=V$.

9 More precisely, a run occurs when, at date 1, the sum of the current cash flow and the value of future cash flows that can be pledged to short-term creditors is less than the face value to be repaid to short-term creditors. This means that, for simplicity, we rule out coordination-driven runs.

10 Although the early empirical literature does not find conclusive evidence of economies of scale and scope in banking activity (see, e.g., the survey by Berger, Hunter, and Timme 1993), more recent papers relying on more recent data and updated methodology document significant economies of scale and scope in banking. For example, Wheelock and Wilson (2012) find evidence of positive returns to scale for most banks, even the largest ones, over the sample period of 1984-2006. Hughes and Mester (2013) find positive returns to scale, with the largest estimated scale economies in the largest size categories (above $\$ 50$ billion in assets). Anderson and Jõeveer (2017) find efficiency benefits for large, complex banks, stemming particularly from a bank's scope (i.e., the diversity of its business lines). They show that bank scope, in turn, is strongly correlated with being a global bank. 
structure: SPOE may be better suited to a G-SIB without redundant systems and with large economies of scale and scope, while MPOE may be more appropriate for a G-SIB with redundant systems in place. $^{11}$

\subsection{National bank regulators}

Whereas the bank is global in its operations, the regulators that act as resolution authorities are national. This assumption, which captures the regulatory status quo, constitutes the key regulatory friction in our model. Specifically, we assume that national regulators follow national objectives and that their sovereignty, combined with the territoriality principle of bankruptcy, allows them to ring-fence assets in their own jurisdiction. In the context of our model, ring-fencing means that the diversifiable cash flow $\Delta$ can be shielded from being used for cross-jurisdictional transfers by the authorities in the jurisdiction where this cash flow materializes (i.e., $\Delta$ can be ring-fenced in the jurisdiction in which it materializes).

In Section 3, we first consider a benchmark case in which the two national regulators jointly maximize global welfare and can credibly commit to a resolution plan ex ante, thereby emulating a supranational regulatory authority. In Section 4, which contains our main results, we then contrast this benchmark with the more realistic scenario in which regulators cannot credibly commit to a resolution plan and act according to the best interests of their own jurisdiction. This noncommitment case captures the regulatory status quo because, in the absence of an international treaty on bank resolution, sovereignty makes it impossible for regulators to credibly commit to cooperating with other regulators in a G-SIB resolution. Therefore, when push comes to shove, regulators will act in their own national interest, and regulatory incentive constraints become key to successful resolution. ${ }^{12}$ While in our model national interests are simply assumed, they arise naturally from political economy considerations. In particular, national regulators are likely to be reluctant to share resources with other jurisdictions in resolution, unless doing so improves the resolution outcome in their own jurisdiction. ${ }^{13}$ To capture this in the simplest

11 The assumption on scale economies implies that, in our framework, a banking structure with two national banks is always dominated by initially setting up a global bank that then sometimes may be split during an SPOE resolution. Intuitively speaking, it is better to lose economies of scale only when necessary.

12 Notwithstanding the efforts of the G-20, the Financial Stability Board, and the Basel Accords, a binding treaty on bank resolution that is enshrined in international law is unlikely to emerge anytime soon. In the absence of such an international treaty, regulators and resolution authorities can form supervisory colleges and issue Memoranda of Understanding (MoUs). However, because MoUs are not legally binding, they generally do not solve the problem that regulators will ultimately act in their national interest. As pointed out by Schoenmaker (2013, p. 15): "The last article of a typical MoU specifies that the arrangements discussed are not legally binding and thus preserve the sovereignty of national supervisors."

13 For example, if sharing resources does not improve outcomes in their own jurisdiction, national regulators are likely to prefer to retain those resources as dry powder should the situation in their own jurisdiction worsen. Alternatively, they may want to improve recovery amounts in their jurisdiction. For example, if holders of TLAC securities are predominantly located in the home jurisdiction, then the home regulator may prefer to sacrifice operations in the host jurisdiction to improve recovery for domestic TLAC investors. 
possible way, we assume that, in resolution, each national regulator maximizes value in its own jurisdiction, disregarding outcomes in the other jurisdiction. Of course, assuming this extreme form of national interest is not necessary, all of our results hold as long as the regulator in jurisdiction $i$ applies a discount to cash flows in jurisdiction $j$.

\subsection{Discussion of model ingredients}

The main goal of our analysis is to isolate the key trade-offs involved in choosing between different resolution regimes for global banks. To do this in a transparent fashion, our model is intentionally simple and a number of model features are simply represented in reduced form. The model could be extended to explicitly microfound these ingredients, but, doing so, would result in a more complicated and much less transparent framework.

Of course, the simplicity of our model necessarily implies that some important aspects of bank resolution are not addressed in our framework. For example, our model assumes that it is always feasible to set aside sufficient loss-absorbing capacity to recapitalize a troubled subsidiary. An interesting extension of our analysis would consider what happens when this is not the case. Moreover, the two-period structure of our model does not deal with some important dynamic issues, such as how banks rebuild loss-absorbing capital over time after a resolution. It also precludes a quantitative analysis of the required amount of loss-absorbing capital. These are certainly interesting issues for future research.

\section{The Need for Minimum Loss-Absorbing Capital Requirements}

A key condition for the proposed G-SIB resolution mechanisms to work is that the bank holding company must have sufficient total loss-absorbing capital (TLAC) — in the form of equity or subordinated long-term debt - to absorb losses of its operating subsidiaries and ensure the safety of their short-term liabilities. Then, even if the operating subsidiary suffers heavy losses, the holding company has sufficient capital to plug the hole. This prevents a creditor run on the operating subsidiaries, which can continue to operate as usual during resolution.

Because the proposed resolution mechanisms rely on sufficient lossabsorbing capital, the first key question in assessing G-SIB resolution is whether the controlling shareholders of the bank holding company will, in fact, find it in their interest to issue a sufficient amount of TLAC. As we show in Proposition 1 , this is generally not the case. The reason is that asymmetric information about long-term cash flows make equity and long-term debt expensive relative to short-term debt. If the asymmetric information discount is large enough, the shareholders of the holding company find it privately optimal to rely on risky short-term debt financing, even at the risk of a default and ensuing creditor run at date 1 . Therefore, a minimum TLAC requirement is an essential complement 
to the proposed G-SIB resolution mechanisms. Proposition 1 summarizes this result. Appendix A provides the detailed derivation of the bank's financing choices and the resultant pooling equilibrium.

Proposition 1. Minimum TLAC requirement. In the absence of a minimum amount of required TLAC, the equityholders of the holding company choose to exclusively rely on risky short-term debt financing when $\bar{p}_{2}<\bar{p}_{2}^{*}(\gamma, L)$. Therefore, when $\bar{p}_{2}<\bar{p}_{2}^{*}(\gamma, L)$, a minimum TLAC requirement is necessary as a complement to both SPOE and MPOE resolution.

Proposition 1 shows that when the asymmetric information friction is sufficiently severe, the equilibrium financing choice of the bank holding company is risky short-term debt. Essentially, when $\bar{p}_{2}$ is sufficiently low relative to the benefits of safe short-term debt and the bank's liquidation value, the shareholders of a bank with high continuation value $\left(C_{2}=V\right)$ find it optimal to risk liquidation at date 1 and lose the benefit of safe short-term debt financing in order to escape the discount associated with long-term financing. ${ }^{14}$ From a social perspective, exclusive reliance on short-term debt when $\bar{p}_{2}<\bar{p}_{2}^{*}(\gamma, L)$ is inefficient. Risky short-term debt has no social benefit (whenever funding is possible with short-term debt, it is also possible with sufficient loss-absorbing capital). Yet risky short-term debt has a social cost, because it leads to inefficient liquidation in the bad state and eliminates the social value of safe short-term debt securities. ${ }^{15}$

\section{MPOE and SPOE Resolution under a Supranational Regulator}

In this section, we compare MPOE and SPOE resolution in a benchmark setting in which the resolution is carried out by a benevolent supranational regulator. This benevolent supranational regulator chooses the resolution regime that maximizes the ex ante expected value of the global bank (equivalent to ex ante surplus) and can commit to implement the required ex post transfers across jurisdictions under SPOE resolution. SPOE resolution has two main advantages. First, the ability to make transfers across subsidiaries in different jurisdictions generates coinsurance benefits, which translate into lower required TLAC for the global bank. This, in turn, increases the bank's capacity to provide banking services through short-term debt issuance. Second, under

14 Banks with low continuation value $\left(C_{2}=0\right)$ have no choice but to mimic this funding choice. Otherwise, they would be revealed as unprofitable.

15 It is worth pointing out that the unwillingness of owners of the banking operation to issue securities that provide enough loss-absorbing capacity is not driven by an expectation of a bailout at date 1 . Even if the government can commit to not bail out banks, the dilution cost associated with claims that provide loss-absorbing capacity implies that the owners of the banking operation may prefer to raise all financing in the form of short-term debt. Of course, if the government faces a commitment problem that could result in ex post bailouts, the incentives to rely on short-term debt are even larger. 
SPOE resolution, the two subsidiaries continue to operate as part of the same global bank even after a resolution, allowing the global bank to fully capture economies of scale and scope from shared services.

\subsection{MPOE resolution}

MPOE involves a separate resolution in each jurisdiction. During this process, the global bank is broken up. ${ }^{16}$ In addition, TLAC for each subsidiary is issued by the respective national holding company and is not shared across jurisdictions. Accordingly, TLAC in each jurisdiction must be set such that the operating subsidiary can meet its short-term liabilities $R_{1}$ even when it generates only $C_{1}^{L}$ at date 1 and the G-SIB is split up during resolution.

To guarantee a successful resolution, the amount of short-term debt issued by the operating subsidiary must be limited to an amount that can be safely serviced or rolled over during a resolution. The maximum amount of short-term debt that can be rolled over at date 1 (with the resolution authority imposing losses on long-term claims if necessary) depends on whether the G-SIB has redundant systems in place. Without redundant systems, splitting up the bank at date 1 leads to a reduction in expected franchise value to $\lambda \bar{p}_{2} V$, meaning that the maximum amount of safe short-term debt that can be issued is $C_{1}^{L}+\lambda \bar{p}_{2} V$. In the presence of redundant systems, the expected franchise value is unaffected by the organizational split resulting from MPOE resolution, and the maximum safe short-term debt is $C_{1}^{L}+\bar{p}_{2} V$. It is efficient to set up redundant systems only if the benefits outweigh the additional ex ante investment $\widetilde{F}-F$. Such redundancy offers two benefits: (1) increased short-term debt issuance $\gamma(1-\lambda) \bar{p}_{2} V$ and (2) no expected separation costs from MPOE resolution $\left(1-p_{1}\right)(1-\lambda) \bar{p}_{2} V$.

Thus, depending on whether redundant systems are set up, the national holding company needs to raise TLAC in the amount of either $F-(1+\gamma)\left(C_{1}^{L}+\right.$ $\left.\lambda \bar{p}_{2} V\right)$ or $\widetilde{F}-(1+\gamma)\left(C_{1}^{L}+\bar{p}_{2} V\right)$. As discussed in detail in Appendix A, it is always in the interest of each national holding company to issue some TLAC in the form of subordinated long-term debt. More precisely, it is privately optimal for each holding company to issue long-term debt with a face value that weakly exceeds the maximum amount of cash that the bank may carry forward from date 1 to date 2. Doing so ensures that all fairly priced (date 1) cash flows are sold to investors, thereby minimizing the amount of financing that has to be raised against $V$, which is subject to a lemons problem. The maximum amount of cash the bank has left after repaying short-term debt at date 1 is given

16 The breakup that occurs as part of MPOE resolution is highlighted, for example, by Tucker (2013), who notes that under SPOE "[t]he group stays together" whereas "[u]nder multiple-point-of-entry or MPE resolutions, by contrast, a group would be split up into some of its parts.” Similarly, the Financial Stability Board (2013, p.13) writes: "Multiple point of entry [...] involves the application of resolution powers by two or more resolution authorities to different parts of the group, and is likely to result in a breakup of the group into two or more separate parts." A breakup is usually necessary under MPOE because, for each point of entry, resolution requires the creation of a new legal entity under separate control from group headquarters (usually by putting part of the group into receivership and then forming a bridge institution), which entails breaking up the global group, at least partially. 
by $C_{1}^{H}+\Delta-R_{1}$. Therefore, under MPOE, the bank will set the face value of long-term subordinated debt to $R_{L T}^{\mathrm{MPOE}} \geq C_{1}^{H}+\Delta-R_{1} \equiv \hat{R}_{L T}^{\mathrm{MPOE}} \cdot{ }^{17}$

\section{Lemma 1. Funding and TLAC under MPOE.}

1. When $\widetilde{F}-F \geq\left(1-p_{1}+\gamma\right)(1-\lambda) \bar{p}_{2} V$, it is not efficient for subsidiaries to set up redundant systems. Each subsidiary issues safe short-term debt with face value $R_{1}^{\mathrm{MPOE}}=C_{1}^{L}+\lambda \bar{p}_{2} V$. Required TLAC per subsidiary is given by $F-(1+\gamma) R_{1}^{\mathrm{MPOE}}=F-(1+\gamma)\left(C_{1}^{L}+\lambda \bar{p}_{2} V\right)$ and is raised by the national holding company via a combination of equity and subordinated long-term debt.

2. When $\widetilde{F}-F<\left(1-p_{1}+\gamma\right)(1-\lambda) \bar{p}_{2} V$, it is efficient for subsidiaries to set up redundant systems. Each subsidiary issues safe short-term debt with face value $R_{1}^{\mathrm{MPOE}}=C_{1}^{L}+\bar{p}_{2} V$. Required TLAC per subsidiary is given by $\widetilde{F}-(1+\gamma) R_{1}^{\mathrm{MPOE}}=\widetilde{F}-(1+\gamma)\left(C_{1}^{L}+\bar{p}_{2} V\right)$ and is raised by the national holding company via a combination of equity and subordinated long-term debt.

3. In both cases, each subsidiary finds it privately optimal to raise at least $\hat{R}_{L T}^{\mathrm{MPOE}}=C_{1}^{H}+\Delta-R_{1}^{\mathrm{MPOE}}$ of the required TLAC as subordinated longterm debt so that all fairly priced cash flows are sold to investors.

4. The subsidiaries are separated during resolution so that each subsidiary bears an effective redundancy or separation cost of $\min \left[\widetilde{F}-F,\left(1-p_{1}+\right.\right.$ $\left.\gamma)(1-\lambda) \bar{p}_{2} V\right]$.

\subsection{SPOE}

SPOE resolution has two advantages over MPOE. First, the diversifiable cash flow $\Delta$ can be shared across the two subsidiaries. We initially focus on the case in which the two jurisdictions always share $\Delta$ equally. ${ }^{18}$ In this case, SPOE raises the minimum cash flow received by each subsidiary at date 1 from $C_{1}^{L}$ to $C_{1}^{L}+\Delta / 2$. Second, even without redundant systems, each subsidiary can always roll over an amount $\bar{p}_{2} V$ of short-term debt at date 1 since the two subsidiaries are not separated under an SPOE resolution. Hence, under SPOE resolution each subsidiary can issue more safe short-term debt, generating larger benefits from liquidity creation. The maximum face value of safe short-term debt (imposing losses on long-term claims in a resolution, if necessary) of each subsidiary under SPOE is

$$
R_{1}^{\mathrm{SPOE}}=C_{1}^{L}+\Delta / 2+\bar{p}_{2} V>R_{1}^{\mathrm{MPOE}} .
$$

TLAC is required if $F>(1+\gamma)\left(C_{1}^{L}+\Delta / 2+\bar{p}_{2} V\right)$, which we assume is the case, and is raised by the global holding company through a combination of

17 The bank's preference to issue a certain amount of TLAC in the form of debt has implications for the current discussion on TLAC composition. We discuss these in Section 6.2.

18 We discuss the possibility of sharing the diversifiable cash flow asymmetrically at the end of Section 4.2. 
subordinated long-term debt and equity. It is again privately optimal for the global holding company to issue subordinated long-term debt with a face value that is at least as large as the amount of cash that is carried forward by the two subsidiaries when they receive the high cash flow: $R_{L T}^{\mathrm{SPOE}} \geq 2 C_{1}^{H}+\Delta-2 R_{1}^{\mathrm{SPOE}} \equiv$ $\hat{R}_{L T}^{\mathrm{SPOE}}$. We summarize the above discussion in the following lemma.

\section{Lemma 2. Funding and TLAC under SPOE.}

1. Under SPOE resolution, each subsidiary issues short-term debt with face value $R_{1}^{\mathrm{SPOE}}=C_{1}^{L}+\Delta / 2+\bar{p}_{2} V$. Required TLAC per subsidiary is given by $F-(1+\gamma) R_{1}^{\mathrm{SPOE}}=F-(1+\gamma)\left(C_{1}^{L}+\Delta / 2+\bar{p}_{2} V\right)$ and is raised by the global holding company via a combination of equity and subordinated long-term debt.

2. The global holding company finds it privately optimal to raise at least $\hat{R}_{L T}^{\mathrm{SPOE}}=2 C_{1}^{H}+\Delta-2 R_{1}^{\mathrm{SPOE}}$ of the required TLAC as subordinated longterm debt.

3. Because the subsidiaries are not separated during resolution, no redundancy or separation costs are incurred.

Comparing Lemmas 1 and 2 establishes our second main result.

Proposition 2. SPOE dominates under supranational regulation. In the benchmark case with a supranational regulator, SPOE resolution dominates MPOE resolution. SPOE resolution allows for a larger provision of liquidity services at the same level of risk and allows the two subsidiaries to capture the benefits from global banking, generating a net social benefit (relative to MPOE resolution) of

$$
\underbrace{\gamma \Delta}_{\begin{array}{c}
\text { additional liquidity services } \\
\text { from diversification }
\end{array}}+\underbrace{2 \min \left[\tilde{F}-F,\left(1-p_{1}+\gamma\right)(1-\lambda) \bar{p}_{2} V\right]}_{\begin{array}{c}
\text { benefits from } \\
\text { global banking }
\end{array}} .
$$

It is efficient to structure global banks as multinational holding companies with shared services across jurisdictions, with national banking subsidiaries sharing TLAC issued by the global holding company.

Proposition 2 highlights the appeal of SPOE resolution: if regulators can commit to cooperate in the midst of a crisis, then SPOE dominates MPOE resolution. The reason is twofold. First, the ability to make cross-jurisdictional transfers under SPOE resolution lowers the amount of required loss-absorbing capital. Accordingly, under SPOE, the G-SIB can increase its issuance of safe short-term debt by a total amount of $\Delta$, resulting in additional surplus arising from liquidity services of $\gamma \Delta$. Second, SPOE resolution allows the G-SIB to fully harness economies of scale or scope that result from global banking, because effective SPOE resolution guarantees that the two subsidiaries 
remain integrated in the global bank organization. This means, in particular, that subsidiaries can reap the benefits of shared services (such as joint cash management or IT systems) without risk of incurring separation costs or the cost of setting up redundant systems. As shown in Proposition 2, this second channel results in an additional increase in surplus of $2 \min \left[\widetilde{F}-F,\left(1-p_{1}+\right.\right.$ $\left.\gamma)(1-\lambda) \bar{p}_{2} V\right]$. Note that this second channel is reinforced by the first: Because benefits from global banking are preserved in resolution, the bank can issue safe short-term debt against future banking activities that, under MPOE, would be lost due to the separation of the bank's activities. In short, a higher value of liquidity services $\gamma$ reinforces the benefit from preserving the global bank, as indicated in the second term of Equation (2).

\section{SPOE and MPOE with National Regulators}

We now depart from the benchmark case of a supranational regulator and enrich the model to reflect the regulatory status quo: bank resolution conducted by national regulators. This section contains the main results of the paper: Ex ante and ex post incentive compatibility constraints significantly limit the applicability of SPOE resolution, despite the conceptual advantages of SPOE resolution discussed in Section 3. First, we show that, from an ex ante perspective, national regulators may not find it in their interest to set up a joint SPOE regime. In this case, MPOE resolution is the only viable option. Second, we show that, even if agreed to beforehand, an SPOE resolution that is implemented by national regulators can fail ex post, because regulators may prefer to ring-fence assets in their own jurisdiction rather than go along with the planned SPOE resolution. When this can be anticipated, regulators should plan for a more robust MPOE resolution instead. Overall, the regulatory status quo, in which the resolution of multinational banks is carried out by national regulators, therefore significantly limits the attainable benefits of SPOE resolution.

\subsection{Ex ante incentive compatibility}

Recall that the objective function of national regulators is to maximize outcomes in their own jurisdictions. We show in this section that this implies, from an ex ante perspective, that national regulators will only agree to set up an SPOE resolution regime if the probabilities of making and receiving transfers are sufficiently symmetric. If one of the two jurisdictions is significantly more likely to make transfers under SPOE resolution, the regulator in that jurisdiction will not agree to put in place an SPOE resolution mechanism, even if this would be efficient in the sense of maximizing overall surplus.

To see this, recall that the additional cash flow $\Delta$ appears in jurisdiction 1 with probability $\theta_{1}$ and in jurisdiction 2 with probability $\theta_{2}$, where $\theta_{1}+\theta_{2}=1$. Consider first the expected benefits from entering an SPOE resolution scheme. If $\Delta$ is shared equally and each of the two subsidiaries increases its issuance of safe short-term debt by the same amount, then a move from MPOE to 
SPOE resolution yields additional liquidity services of value $\gamma \Delta / 2$ in each jurisdiction. Moreover, SPOE resolution allows the bank to capture economies of scale and scope benefits from global banking, which per jurisdiction amount to the lesser of the cost of setting up redundant systems and expected separation costs, $\min \left[\widetilde{F}-F,\left(1-p_{1}+\gamma\right)(1-\lambda) \bar{p}_{2} V\right]$.

The cost of SPOE resolution, from the perspective of a national regulator, is the expected net transfer that has to be made to the other jurisdiction in the low cash-flow state. Even though this is a pure transfer when looking at the two subsidiaries as a whole, the assumption that regulators follow national objectives implies that, in their eyes, this transfer constitutes a loss for their jurisdiction. ${ }^{19}$ Consider the regulator in jurisdiction 1 under SPOE. With probability $\left(1-p_{1}\right) \theta_{1}$, jurisdiction 1 makes a transfer of $\Delta / 2$ to jurisdiction 2 . With probability $\left(1-p_{1}\right) \theta_{2}$, jurisdiction 1 receives a transfer of size $\Delta / 2$ from jurisdiction 2 . The net expected transfer that jurisdiction 1 makes to jurisdiction 2 is therefore $\frac{\Delta}{2}\left(1-p_{1}\right)\left(\theta_{1}-\theta_{2}\right)$. The regulator in jurisdiction 1 is then willing to enter into an SPOE resolution regime if the benefits from increased liquidity provision and shared services given in Equation (2) outweigh the cost in the form of expected net transfers. Because both regulators must agree to set up an SPOE resolution regime, an analogous condition has to hold for the regulator in jurisdiction 2. Combining the ex ante incentive constraints of both regulators, we then arrive at the following proposition.

Proposition 3. Ex ante incentive compatibility of SPOE resolution. SPOE bank resolution is ex ante incentive compatible only if the benefit from increased banking activity and the gains from global banking in each jurisdiction outweigh the expected net transfer payments to the other jurisdiction. This requires that cash flows in each jurisdiction are sufficiently symmetric:

$$
\left|\theta_{1}-\theta_{2}\right| \leq \frac{\gamma}{1-p_{1}}+\frac{2}{\Delta} \min \left[\frac{\widetilde{F}-F}{1-p_{1}},\left(1+\frac{\gamma}{1-p_{1}}\right)(1-\lambda) \bar{p}_{2} V\right]
$$

Proposition 3 establishes that ex ante implementation of SPOE requires sufficient symmetry in payoffs across jurisdictions. The left-hand side of the ex ante IC constraint (3) states that the probabilities $\theta_{i}$ of receiving the diversifiable cash flow $\Delta$ must be sufficiently symmetric across the two jurisdictions. When one jurisdiction is significantly more likely to make a transfer under SPOE, the regulator of that jurisdiction does not find it in its interest to set up an SPOE resolution scheme. The right-hand side of the ex ante IC constraint (3) states that

19 In our discussion of the ex ante and ex post incentive constraints, we will somewhat loosely refer to transfers that are made from one jurisdiction to the other under SPOE resolution. In practice, making these transfers involves upstreaming $\Delta / 2$ from the operating subsidiary that received $\Delta$ to the global holding company, and then downstreaming it to the operating subsidiary in need of resources. Crucially, at some point, this process involves moving $\Delta / 2$ across jurisdictional lines, which opens up the possibility of ring-fencing by the regulator required to make the transfer. 
SPOE is more likely to be ex ante incentive compatible when the incremental social benefit from banking activity $\gamma$ is large and significant returns to scale and scope to global banking are present. A larger benefit from additional banking activity and from returns to scale and scope makes it more likely that nationally minded regulators agree to SPOE, even if for one jurisdiction this means making a net expected transfer to the other jurisdiction. Overall, the implication is that when national regulators are in charge of designing a resolution scheme for multinational banks, they will choose a more efficient SPOE resolution mechanism only if the costs of SPOE resolution are shared sufficiently symmetrically across jurisdictions.

Let us make two brief observations regarding Proposition 3. First, the conclusion that asymmetry across jurisdictions can prevent regulators from setting up an efficient resolution regime echoes Dell'Ariccia and Marquez (2006), who show that national regulators may not agree on a centralized supranational capital regulation framework when these regulators differ in the extent to which they are captured by their domestic financial industries. Our analysis shows that heterogeneity across jurisdictions is also an obstacle in the context of multinational bank resolution. Second, Proposition 3 rules out transfer payments between regulators. Our assumption is that such transfer payments are politically infeasible. The protracted discussions about the European deposit insurance scheme illustrate the reality that reaching agreement on such transfers can be extremely difficult. If such transfer payments were possible, then the regulator in the jurisdiction more likely to receive a transfer under SPOE resolution could make an appropriate transfer payment to induce the other regulator to join the resolution mechanism.

\subsection{Ex post incentive compatibility}

We now shift our focus to ex post incentive compatibility, perhaps the biggest obstacle to a successful SPOE resolution. Assume that the two regulators have agreed to an SPOE resolution. Then the key issue ex post (after the low state has been realized and the global bank has to be resolved) is that sovereignty allows the regulator in each jurisdiction to unilaterally ring-fence assets, thereby preventing the transfer of resources $\Delta / 2$ necessary for a successful SPOE resolution. The question is whether the regulator in the jurisdiction that receives the additional cash flow $\Delta$ finds it in its own interest to make the required transfer of $\Delta / 2$ to the other jurisdiction.

Our model indicates two ways in which a planned SPOE resolution can break down ex post. First, when the cash flow $\Delta$ materializes in the jurisdiction in which the global holding company is located (the home jurisdiction), the home regulator may refuse to make the required transfer to the operating subsidiary in the other jurisdiction (the host jurisdiction). This happens when the transfer of $\Delta / 2$ to the host institution is larger than the home jurisdiction's expected loss should the subsidiary in the other jurisdiction face a bank run and be liquidated. This cost consists of the loss of shared services $(1-\lambda) \bar{p}_{2} V$. Second, when 
the cash flow $\Delta$ materializes in the host jurisdiction, the regulator in the host jurisdiction may prefer to ring-fence assets in response to an SPOE resolution in the home jurisdiction. Again, such ring-fencing is privately optimal when the transfer of $\Delta / 2$ to the home subsidiary is larger than the expected loss of shared services $(1-\lambda) \bar{p}_{2} V$. Assuming equal continuation values $V$ in the two jurisdictions, these two cases reduce to the same incentive constraint, as summarized in the following proposition.

Proposition 4. Ex post incentive compatibility of SPOE resolution. In the presence of national regulators that cannot commit to ex post transfers, SPOE resolution is not incentive compatible whenever the required ex post transfer across jurisdictions is larger than the loss of global banking benefits that results from unilateral ring-fencing,

$$
\frac{\Delta}{2}>(1-\lambda) \bar{p}_{2} V
$$

Proposition 4 has two main implications. First, when the cross-jurisdictional transfer that is required under SPOE is too large, the necessary incentive constraint (4) is not satisfied, leading to a breakdown of the SPOE resolution scheme. Such an ex post breakdown of a planned SPOE resolution is, of course, the worst possible outcome: having planned for an SPOE resolution, the ex post unwillingness of regulators to make required transfers leaves no other option but a disorderly liquidation following a bank run or a tax-funded bailout, precisely the scenarios that bank resolution is meant to prevent. Second, Proposition 4 shows that incentive compatible SPOE resolution is facilitated by operational complementarities across jurisdictions that arise from ring-fencing (as captured by a low $\lambda$ ). It is precisely the loss of complementarities across the two bank affiliates that incentivizes regulators not to ring-fence assets ex post. ${ }^{20}$

An assumption maintained in the analysis above is that the additional shortterm debt issued under SPOE is allocated symmetrically across jurisdictions. However, Propositions 3 and 4 also help us shine a light on whether incentives under SPOE could be restored by allocating this additional short-term debt asymmetrically. Indeed, from Proposition 3 we can see that, by allowing the operating subsidiary in the jurisdiction that is more likely to receive $\Delta$ to issue more of the additional short-term debt, the ex ante incentive constraint (3) can be satisfied in situations where a symmetric allocation of the benefits from additional short-term debt across jurisdictions would not be ex ante incentive compatible. At the same time, however, Proposition 4 shows that this would make the ex post incentive constraint (4) harder to satisfy. In particular,

20 In a dynamic setting, Proposition 4 suggests that making smaller transfers continuously before resolution may allow a G-SIB to efficiently reduce the probability of a large required transfer in resolution. Ervin (2017) provides a more detailed discussion of using small transfers to reduce such "misallocation risk." 
successful resolution is guaranteed only when the ex post IC is satisfied for the maximum necessary transfer. The maximum transfer, however, is larger than $\Delta / 2$ when short-term debt is allocated asymmetrically across jurisdictions.

\subsection{Bank resolution and the structure of global banks}

Proposition 4 generates a clear prediction as to which types of global banks can be resolved successfully under SPOE: Cross-jurisdictional complementarities must be large enough to render transfers during resolution incentive compatible. Banks for which the incentive constraint is unlikely to be satisfied, on the other hand, should plan for MPOE resolution. Moreover, banks that opt for MPOE resolution may find it efficient to make an ex ante investment in redundant systems. This is the case whenever the additional cost of setting up redundant systems, $\widetilde{F}-F$, is smaller than the expected separation costs under MPOE, $\left(1-p_{1}+\gamma\right)(1-\lambda) \bar{p}_{2} V$. Jointly, the ex post incentive constraint and the ex ante choice to set up redundant system then characterize the link between bank resolution and the risk profile and operational structure of global banks.

\section{Proposition 5. Bank resolution and the structure of global banks.}

1. When $\frac{\Delta}{2} \leq \bar{p}_{2}(1-\lambda) V$, SPOE resolution is ex post incentive compatible and it is efficient for global banks to adopt a multinational holding company structure and maximize reliance on shared services.

2. When $\frac{\Delta}{2}>\bar{p}_{2}(1-\lambda) V$, SPOE resolution is not ex post incentive compatible and, therefore, MPOE resolution based on separate national holding companies is preferable.

3. Under MPOE resolution, setting up redundant systems that facilitate the separation of banking subsidiaries during a resolution is efficient when $\widetilde{F}-F<\left(1-p_{1}+\gamma\right)(1-\lambda) \bar{p}_{2} V$.

According to Proposition 5, the efficient choice between SPOE and MPOE depends on the structure of a global bank's business risks (captured by $\Delta$ ) and the size of the complementarities between operating subsidiaries in different jurisdictions (captured by $\lambda$ ). Therefore, a one-size-fits-all approach to G-SIB resolution is unlikely to be efficient. Rather, a bank's resolution plan should correspond to a bank's cash-flow risk and operational structure.

Figure 2 illustrates this correspondence. Specifically, banks for which SPOE resolution is ex post incentive compatible should be resolved under SPOE. In the figure, these banks are located above the 45-degree line; they are characterized by relatively large scale or scope economies (i.e., large $\lambda$ ) and low-to-moderate idiosyncratic cash-flow risk across jurisdictions (i.e., $\Delta$ not too large). Because these banks will be resolved as a whole, they should also capitalize on their economies of scale by relying on shared systems, rather than investing in redundant systems. In contrast, banks with modest economies of scale and scope (small $\lambda$ ) and significant diversifiable cash-flow risk (large $\Delta$ ) cannot be resolved under SPOE in an incentive compatible fashion. Therefore, these banks 


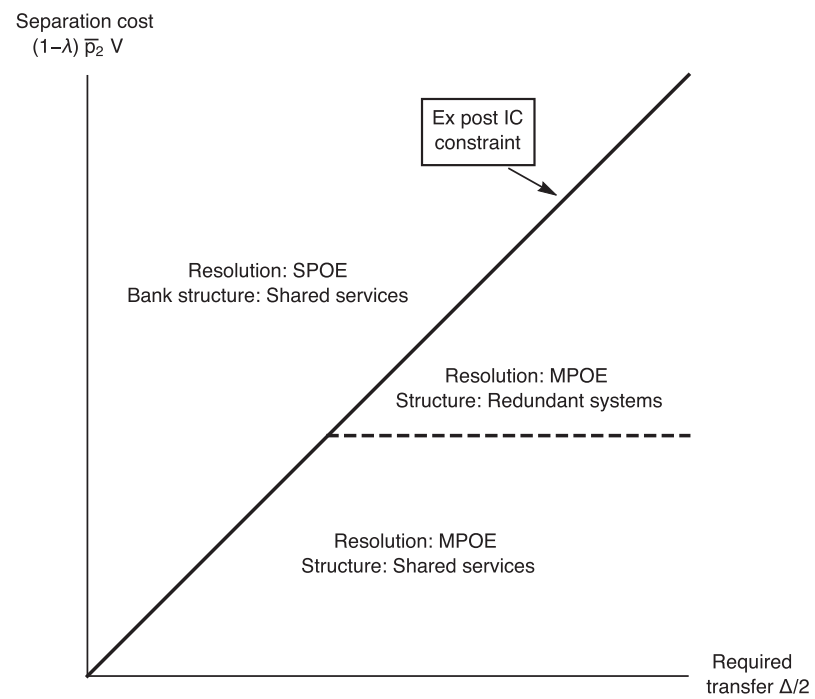

Figure 2

Bank resolution (MPOE or SPOE) and bank structure

The figure illustrates the correspondence between bank resolution and bank structure established in Proposition 5 . The $x$-axis plots the required ex post transfer under SPOE resolution $\Delta / 2$. The $y$-axis plots the loss of franchise value that results when subsidiaries with shared services are separated as part of an MPOE resolution $(1-\lambda) \bar{p}_{2} V$. The 45-degree line represents the ex post incentive constraint for successful SPOE resolution (4). Whenever the ex post incentive constraint is satisfied (i.e., to the left of the 45-degree line), SPOE resolution combined with a bank structure with shared services dominates MPOE resolution. When the ex post incentive constraint is not satisfied (to the right of the 45-degree line) SPOE fails and therefore MPOE resolution is efficient. Under MPOE resolution, bank structure should respond through an ex ante investment in redundant systems when the cost of such an investment is less than the expected separation cost (i.e., $\widetilde{F}-F<\left(1-p_{1}+\gamma\right)(1-\lambda) \bar{p}_{2} V$ ), as illustrated by the dashed line.

should adopt an MPOE resolution plan. In the figure, these banks are located below the 45-degree line. Because these banks will be split up in resolution, setting up redundant systems ex ante, in order to prevent the ex post loss of value that arises when operating subsidiaries are separated in resolution, may be efficient.

To give a concrete example, consider a decentralized G-SIB with small cross-jurisdictional complementarities, such as HSBC or Santander. For these banks, SPOE resolution is unlikely to be incentive compatible, and a more robust MPOE resolution that does not require incentive compatibility across jurisdictions is appropriate. Consistent with this prediction, the HSBC (2015) annual report states that "[i]t is our view that a strategy by which the Group breaks up at a subsidiary bank level at the point of resolution (referred to as a Multiple Point of Entry) is the optimal approach, as it is aligned to our existing legal and business structure." In the same annual report, HSBC also states a preference for setting up redundant systems: "[W]e are working with our regulators to mitigate or remove critical inter-dependencies between our subsidiaries to further facilitate the resolution of the Group." Therefore, HSBC 
would be located in the top-right region illustrated in Figure 2. In contrast, a GSIB with significant complementarities across jurisdictions, such as JPMorgan Chase, would be located in the top-left region of Figure 2 and is resolved more efficiently under SPOE. Indeed, in its 2017 resolution plan, JPMorgan Chase states that "[W]e have determined that the best strategy for resolving our firm $[\ldots]$ is a Single Point of Entry resolution strategy."

\subsection{Optimal ex post incentive compatible resolution: A hybrid approach}

Up to now our analysis focused on a comparison between a pure SPOE resolution (all loss-absorbing capital is shared across jurisdictions) and a pure MPOE resolution (all loss-absorbing capital is issued separately at the national level). We now build on these results to show that, when SPOE is not ex post incentive compatible, the constrained optimal resolution mechanism is a hybrid model. In this hybrid model, some loss-absorbing capital is still shared across jurisdictions, but a sufficiently large amount is effectively preassigned to a particular jurisdiction to guarantee incentive compatibility.

The idea behind this hybrid model is relatively straightforward. As shown above, a pure SPOE resolution breaks down when the transfer that is required during resolution violates the ex post incentive constraint. In this case, a pure MPOE approach can still provide a successful resolution, but it sacrifices all of the benefits from resource sharing across jurisdictions and resolving the bank as a global whole. The constrained optimal model lies somewhere in between: It reduces cross-jurisdictional transfers to an amount that just satisfies the ex post IC constraint (i.e., Equation (4) holds with equality). Of course, relative to SPOE, the smaller size of the cross-jurisdictional transfer has to be offset by an increase in loss-absorbing capital in each jurisdiction. The following proposition formalizes this intuition.

Proposition 6. Constrained optimal bank resolution. Assume that $\Delta / 2>$ $\bar{p}_{2}(1-\lambda) V$, so that the ex post incentive constraint for SPOE resolution (4) is violated. The constrained optimal resolution scheme limits the amount of shortterm debt issued by each operating subsidiary such that the required transfer in resolution just satisfies the ex post IC constraint,

$$
T^{*}=\bar{p}_{2}(1-\lambda) V
$$

where $T^{*}<\Delta / 2$. This allows each operating subsidiary to issue safe short-term debt of $R_{1}^{*}=C_{1}^{L}+\bar{p}_{2} V+T^{*}$, where $R_{1}^{\mathrm{MPOE}}<R_{1}^{*}<R_{1}^{\mathrm{SPOE}}$.

From a practical perspective, the constrained optimal resolution mechanism characterized in Proposition 6 can be implemented through judicious prepositioning of TLAC in intermediate national holding companies. In particular, loss-absorbing capital that is shared across jurisdictions is issued by the global holding company. Loss-absorbing capital that is not shared across jurisdictions is issued by intermediate national holding companies. The 
presence of this prepositioned TLAC and the associated reduction in short-term debt in each jurisdiction lower the required transfer during resolution to $T^{*}$, so that the ex post incentive constraint is just satisfied. While this hybrid model does not generate the same liquidity benefits as the benchmark case of SPOE under a single supranational regulator, it exploits the advantages of shared lossabsorbing capital and global resolution as much as is incentive compatible under the constraints imposed by national regulators. As we discuss in more detail in Section 6, this hybrid resolution model provides a framework to assess the recent policy proposals that have advocated the use of "prepositioned resources" to limit the ex post reliance on "contributable resources" (i.e., transfers that rely on the cash flow $\Delta$ ).

\section{Bank Incentives under MPOE and SPOE Resolution}

Under a bank resolution model in which loss-absorbing capital is always sufficient to absorb operating losses, the usual disciplining role of debt is muted. This makes equity-based incentives for management particularly important. Accordingly, an important question is whether MPOE or SPOE resolution results in better incentives for managers running the operating subsidiaries.

In this section, we extend our model to analyze equity-based incentives for managers of the G-SIB's operating subsidiaries. To do so, we introduce a simple managerial effort problem into our model. Specifically, we assume that each subsidiary manager has to exert effort $e \in\{0,1\}$ to generate the diversifiable cash flow $\Delta .^{21}$ Subsidiary $i$ receives $\Delta$ with probability $\theta_{i}$ if its manager exerts effort $(e=1)$. On the other hand, if the manager of subsidiary $i$ does not exert effort $(e=0)$, this subsidiary receives $\Delta$ only with a lower probability of $\theta_{i}-\epsilon$. Exerting effort is costly for the manager because it results in the loss of a nonpecuniary private benefit $B>0$. As before, we assume that $\theta_{1}+\theta_{2}=1$, so that the cash flow $\Delta$ is generated for sure (in one of the jurisdictions) if both subsidiaries exert effort, but $\Delta$ is received with probability less than one if at least one subsidiary manager shirks. For ease of exposition, we initially focus on the case in which TLAC takes the form of an outside equity stake $\alpha_{0}$. We then turn to the issue of TLAC composition at the end of the section. ${ }^{22}$

\subsection{Incentives under SPOE resolution}

As we have seen, the benefits of SPOE resolution stem to a significant extent from the ability to share the cash flow $\Delta$ across jurisdictions. But will operating

21 We focus on incentives to produce $\Delta$, because who receives this cash flow is critically affected by the choice of resolution model. In particular, under SPOE resolution, the operating subsidiary that generates $\Delta$ loses half of this cash flow as part of the transfer that occurs in resolution. Our model also allows us to study incentives to produce the high aggregate cash flow $C_{1}^{H}$. We explore this extension in the Online Appendix.

22 We also abstract from the issue of setting up redundant systems, which is orthogonal to the incentive issues studied in this section. 
subsidiaries have sufficient incentives to produce this cash flow given the prospect that it may be transferred to the operating subsidiary in the other jurisdiction in a resolution?

To gauge these incentives, we need to make an assumption about how profits are divided between the national banking subsidiaries. The most natural assumption is that the global holding company pays out a fraction $\alpha_{0}^{\mathrm{SPOE}}$ of total profits to outside shareholders, and that national operating subsidiaries receive the remaining fraction $1-\alpha_{0}^{\mathrm{SPOE}}$ of the profits that were generated in that particular jurisdiction.

Under SPOE, inside equityholders do not receive a payoff in the low aggregate cash-flow state. In particular, in the low cash-flow state, $\Delta$ is shared across jurisdictions to repay short-term debt in each subsidiary. ${ }^{23}$ Acting in the interest of the inside equityholders of the national operating subsidiaries, the manager of operating subsidiary $i$ then exerts effort if the payoff given effort is larger than the payoff when not exerting effort and enjoying the private benefit:

$$
\begin{aligned}
& p_{1}\left(1-\alpha_{0}^{\mathrm{SPOE}}\right)\left[C_{1}^{H}+\theta_{i} \Delta-R_{1}^{\mathrm{SPOE}}+p_{2}^{i} V\right] \\
& \quad \geq p_{1}\left(1-\alpha_{0}^{\mathrm{SPOE}}\right)\left[C_{1}^{H}+\left(\theta_{i}-\epsilon\right) \Delta-R_{1}^{\mathrm{SPOE}}+p_{2}^{i} V\right]+B .
\end{aligned}
$$

Collecting terms and simplifying, under SPOE it is optimal for the manager of each national operating subsidiary to exert effort if

$$
\left(1-\alpha_{0}^{\mathrm{SPOE}}\right) p_{1} \epsilon \Delta \geq B .
$$

If the manager exerts effort, $\alpha_{0}^{\mathrm{SPOE}}$ satisfies the break-even condition

$$
\alpha_{0}^{\mathrm{SPOE}}\left[p_{1}\left(2 C_{1}^{H}+\Delta-2 R_{1}^{\mathrm{SPOE}}+2 \bar{p}_{2} V\right)\right] \geq 2\left[F-(1+\gamma) R_{1}^{\mathrm{SPOE}}\right],
$$

so that sufficient TLAC for both operating subsidiaries is raised. Substituting for $R_{1}^{\mathrm{SPOE}}=C_{1}^{L}+\bar{p}_{2} V+\Delta / 2$ yields a minimum required outside equity stake of

$$
\alpha_{0}^{\mathrm{SPOE}}=\frac{F-(1+\gamma)\left[C_{1}^{L}+\bar{p}_{2} V+\Delta / 2\right]}{p_{1}\left(C_{1}^{H}-C_{1}^{L}\right)} .
$$

Based on the incentive constraint (7) and the equilibrium value of the outside equity stake (9), we then see that resolution has to be sufficiently unlikely (i.e., $p_{1}$ has to be sufficiently high) for the manager to be willing to exert effort to produce $\Delta$.

Proposition 7. Under SPOE resolution, operating subsidiary managers exert effort to produce $\Delta$ only if the resolution state is sufficiently unlikely, $p_{1} \geq p_{1}^{*} \equiv$ $\underline{p}_{1}+\frac{B}{\epsilon \Delta}$, where $\underline{p}_{1}=\frac{F-(1+\gamma) R_{1}^{\mathrm{SPOE}}}{C_{1}^{H}-C_{1}^{L}}$. If $p_{1}<p_{1}^{*}, \Delta$ is not always produced and a successful SPOE resolution cannot be guaranteed.

23 In fact, recall that the face value of short-term debt is higher under SPOE, so that $\Delta$ is always paid out to short-term debtholders. 
To understand the condition in Proposition 7, note that $p_{1}$ is the minimum value for $p_{1}$ such that the bank can raise enough funds with TLAC securities to fund the initial setup cost $F$ (by setting $\alpha_{0}^{\mathrm{SPOE}}=1$ ). The proposition states that on the nonempty interval $\left[\underline{p}_{1}, p_{1}^{*}\right)$ the moral hazard problem generated by the private benefit $B$ impedes successful SPOE resolution. In this case, a successful SPOE resolution cannot be guaranteed and it is therefore more efficient to set up a more robust MPOE resolution.

\subsection{Incentives under MPOE resolution}

SPOE and MPOE differ along two aspects with respect to incentives to produce the diversifiable cash flow $\Delta$. The first is that MPOE is designed to be robust with respect to whether $\Delta$ is available or not. In this sense, whether $\Delta$ is produced is irrelevant for a successful MPOE resolution. The second aspect is operational efficiency. In particular, the choice of the resolution regime affects the bank manager's incentives to produce the cash flow $\Delta$. As we show below, taken together these two forces imply that MPOE resolution often results in a more resilient but potentially less efficient G-SIB.

Let us first briefly point out the key robustness property of MPOE resolution with respect to incentives to produce $\Delta$. Since TLAC for each subsidiary is set to cover the shortfall $R_{1}^{\mathrm{MPOE}}-C_{1}^{L}=\bar{p}_{2} \lambda V$, under MPOE a run on short-term debt can be avoided by writing down claims on the bank's continuation value, regardless of whether $\Delta$ materializes. Therefore, successful resolution under MPOE does not depend on the presence of adequate managerial incentives to produce $\Delta$. Of course, as shown above, this robustness comes at the expense of reducing the amount of liquidity services provided by the G-SIB and reducing scale economies from global banking.

We now show how incentives to produce $\Delta$ differ between SPOE and MPOE resolution. To do this, we derive the analogue to incentive constraint (7) under MPOE resolution. While the payoff in the high cash-flow state can be calculated in analogous fashion, a key difference to SPOE is that, under MPOE, inside equityholders sometimes also receive a payoff in the low cash-flow state. In particular, with probability $\left(1-p_{1}\right) \theta_{i}$, the subsidiary receives $C_{1}^{L}+\Delta$. In this case, because $\Delta$ is available to reduce outstanding short-term debt, equityholders are only partially wiped out in resolution. Specifically, the fraction $x$ of equity that is wiped out satisfies $x \bar{p}_{2} \lambda V=$ $\bar{p}_{2} \lambda V-\Delta$, such that inside equityholders receive an expected date-2 payoff of $(1-x)\left(1-\alpha_{0, i}^{\mathrm{MPOE}}\right) p_{2}^{i} \lambda V=\left(1-\alpha_{0, i}^{\mathrm{MPOE}}\right) \frac{p_{2}^{i}}{\bar{p}_{2}} \Delta .^{24}$ When the manager does not exert effort $(e=0)$, inside equityholders' payoffs are analogous, except that $\Delta$ is received only with probability $\theta_{i}-\epsilon$.

24 The cash flow $\Delta$ is paid out to reduce short-term debt for two reasons. First, the high-type bank strictly prefers to do so, because raising funds against future cash flows is costly as it occurs at a discount. As before, the low-type bank will mimic the high type. Second, legal constraints make it difficult for the bank to effectively pay out a dividend $\Delta$ just before going into resolution. 
Exerting effort is individually optimal for the manager of subsidiary $i$ if producing $\Delta$ with probability $\theta_{i}$ leads to a higher payoff for the manager than receiving $\Delta$ with probability $\theta_{i}-\epsilon$ and enjoying the private benefit $B$. Simplifying terms analogously to the derivation of (7), the incentive constraint under MPOE reduces to

$$
\left(1-\alpha_{0, i}^{\mathrm{MPOE}}\right)\left[p_{1} \epsilon \Delta+\left(1-p_{1}\right) \frac{p_{2}^{i}}{\bar{p}_{2}} \epsilon \Delta\right] \geq B .
$$

To raise sufficient TLAC, the outside equity stake under MPOE must satisfy

$$
\alpha_{0, i}^{\mathrm{MPOE}}\left[p_{1}\left(C_{1}^{H}+\theta_{i} \Delta-R_{1}^{\mathrm{MPOE}}+\bar{p}_{2} V\right)+\left(1-p_{1}\right) \theta_{i} \Delta\right] \geq F-(1+\gamma) R_{1}^{\mathrm{MPOE}},
$$

where the payoff in the low cash-flow state is the outside equityholders' expectation of the (partially diluted) equity stake $\left(1-p_{1}\right) \theta_{i}(1-x) \bar{p}_{2} \lambda V=$ $\left(1-p_{1}\right) \theta_{i} \Delta$. Substituting in for $R_{1}^{\mathrm{MPOE}}=C_{1}^{L}+\bar{p}_{2} \lambda V$, this yields a minimum required outside equity stake of

$$
\alpha_{0, i}^{\mathrm{MPOE}}=\frac{F-(1+\gamma)\left(C_{1}^{L}+\bar{p}_{2} \lambda V\right)}{p_{1}\left[C_{1}^{H}-C_{1}^{L}+\bar{p}_{2}(1-\lambda) V\right]+\theta_{i} \Delta} .
$$

Comparing the incentive constraints (7) and (10) reveals that differences in incentives under MPOE and SPOE resolution are driven by two effects. First, incentives under SPOE are muted because the operating subsidiary never receives the cash flow $\Delta$ in the low cash-flow state. Effectively, the higher amount of short-term debt under SPOE results in debt overhang, reducing the manager's incentive to produce $\Delta$. Second, the required outside equity stakes $\alpha_{0}$ differ across MPOE and SPOE, as illustrated by Equations (9) and (12). Therefore, incentives to exert effort are stronger under SPOE only if the inside equity stake that can be retained under SPOE is sufficiently larger, outweighing the debt overhang effect. The following proposition summarizes these results.

\section{Proposition 8. Incentives under MPOE and SPOE.}

1. Operating subsidiary $i$ has stronger incentives to exert effort to produce $\triangle$ under SPOE than under MPOE when the retained inside equity stake under SPOE is sufficiently larger than the inside equity stake that can be retained under MPOE,

$$
\frac{1-\alpha_{0}^{\mathrm{SPOE}}}{1-\alpha_{0, i}^{\mathrm{MPOE}}}>1+\frac{1-p_{1}}{p_{1}} \frac{p_{2}^{i}}{\bar{p}_{2}} .
$$

2. When the probabilities of receiving the additional cash flow $\Delta$ are symmetric across jurisdictions $\left(\theta_{1}=\theta_{2}=\frac{1}{2}\right)$, a sufficient condition for better incentives for subsidiary $i$ under SPOE is that

$$
\frac{\Delta}{2}>\frac{\left(1-p_{1}\right)\left(C_{1}^{H}-C_{1}^{L}\right)}{1+\gamma} \frac{p_{2}^{i}}{\bar{p}_{2}} .
$$


3. When the probabilities of receiving the additional cash flow $\Delta$ are asymmetric across jurisdictions $\left(\theta_{1} \neq \theta_{2}\right)$, it becomes easier to sustain incentives for both operating subsidiaries under SPOE, because incentives are reduced for one of the two subsidiaries under MPOE.

Proposition 8 shows that incentives under SPOE and MPOE resolution depend on the trade-off between two forces. On the one hand, SPOE dampens incentives because some of the cash flows generated by the manager are transferred to the other jurisdiction, which makes it difficult to sustain high effort. On the other hand, SPOE can allow the firm to retain a larger inside equity stake, which helps align incentives. Part 1 of Proposition 8 shows that the net effect of these two forces is positive if and only if the retained equity stake under SPOE is sufficiently larger than the retained equity stake under MPOE. Of course, the retained equity stakes are endogenous quantities. To gain intuition for when the condition given in part 1 of Proposition 8 holds, it is useful to first consider the symmetric case $\left(\theta_{1}=\theta_{2}=1 / 2\right)$. As shown in part 2 of Proposition 8 , in the symmetric case incentives to exert effort are stronger under SPOE when $\Delta$ is sufficiently large. Part 3 considers the asymmetric case $\left(\theta_{1} \neq \theta_{2}\right)$. Whereas asymmetry does not affect incentives for operating subsidiaries under SPOE, it worsens incentives for one of the two operating subsidiaries under MPOE, because the operating subsidiary for which $\theta_{i}<1 / 2$ has to issue a larger outside equity stake. Therefore, relative to SPOE, under MPOE it is harder to sustain incentives for both operating subsidiaries to produce $\Delta$, as stated in part 3 of Proposition $8 .^{25}$

\subsection{The effect of TLAC composition on incentives}

Above, we have assumed for simplicity that the bank issues TLAC in the form of an equity stake. We now relax this assumption and allow for TLAC in the form of equity and debt. The key novel effect is that TLAC composition can affect the operating subsidiaries' incentives to produce $\Delta$.

The easiest way to see how TLAC in the form of debt affects incentives is from the incentive constraints (7) and (10). Consider first the effect on effort incentives of a small amount of long-term debt under SPOE. In the high aggregate-cash-flow state, resolution does not occur, and $R_{L T}$ is repaid in full regardless of whether $\Delta$ is produced. Therefore, the only change in the incentive constraint (7) is an increase in the inside equity stake $1-\alpha^{\mathrm{SPOE}}$ that results when a larger fraction of the bank's TLAC is raised in the form of debt. With a larger retained equity stake, the incentive constraint (7) becomes easier

25 In our analysis of moral hazard concerns, we focused on how operating subsidiary managers can be incentivized through equity participation to offset the lack of discipline from debt markets. Alternatively, moral hazard concerns could be addressed by monitoring subsidiary managers. The analysis above can be straightforwardly adapted to this alternative specification by focusing on the holding company manager's incentives to monitor subsidiaries, with $e \in\{0,1\}$ standing for monitoring effort as opposed to the effort needed to produce the cash flow $\Delta$. 
to satisfy. Under SPOE, more TLAC in the form of debt therefore improves the operating subsidiaries' incentives to produce $\Delta$, an illustration of the classic incentive property of debt, as pointed out by Jensen and Meckling (1976). ${ }^{26}$

Under MPOE, the effect of long-term debt on incentives is more subtle. As the incentive constraint (10) shows, a second effect counteracts the improvement in incentives. In the low aggregate-cash-flow state, the presence of long-term debt reduces the payoff to (inside and outside) equityholders from $\frac{p_{2}^{i}}{\bar{p}_{2}} \epsilon \Delta$ to $\max \left[\frac{p_{2}^{i}}{\bar{p}_{2}} \epsilon \Delta-R_{L T}, 0\right]$. This payoff reduction counteracts the increase in the size of the retained equity stake $1-\alpha^{\mathrm{MPOE}}$. The net effect of long-term debt on incentives to produce $\Delta$ is therefore ambiguous. In particular, in contrast to SPOE, it is possible that incentives to produce $\Delta$ are strongest under MPOE when TLAC is all equity.

\section{Discussion}

In this section, we link our analysis to the current policy discussion on bank resolution, focusing on recent resolution proposals by the Financial Stability Board (FSB) and the Federal Reserve, the issue of TLAC composition, the possibility that resolution areas include more than two countries, and the legal structures of global banks (i.e., the choice between branches and subsidiaries).

\subsection{Assessing the FSB and Federal Reserve TLAC policy proposals}

The policy proposals put forward by the Financial Stability Board (2015) and the Federal Reserve (2015) broadly advocate an SPOE approach and address incentive and ring-fencing issues through the prepositioning of TLAC and liquidity. ${ }^{27}$ In their general contours, the FSB and Fed G-SIB resolution proposals therefore reflect the hybrid resolution model discussed in Section 4.4 .

As highlighted by our analysis, one of the key challenges in G-SIB resolution under SPOE is ensuring that national regulators are willing to cooperate. Such cooperation cannot be taken for granted. National regulators may prefer to ringfence domestic assets rather than cooperate in a cross-border SPOE resolution that involves transfers to recapitalize operations in another jurisdiction. In our model, this issue arises when the required transfer of $\Delta / 2$ is so large that ring-fencing $\Delta$ becomes privately optimal for national regulators.

One potential concern with TLAC in the form of debt is that it may create risk-shifting incentives. For a model that examines the trade-off between the incentive and risk-shifting properties of debt and equity-based TLAC, but without our focus on MPOE and SPOE resolution, see Mendicino, Nikolov, and Suarez (2018).

27 In our model, liquidity corresponds to the minimum (total) cash flow $2 C_{1}^{L}+\Delta$, where $C_{1}^{L}$ can be prepositioned in each jurisdiction, whereas $\Delta$ cannot be prepositioned because ex ante it is not known where this cash flow will materialize. 
The FSB and Fed resolution proposals recognize the challenge of ensuring coordination among regulators. In particular, U.S. regulators have asked GSIBs based in the United States to adopt corporate structures that limit the need for action by foreign regulators under SPOE resolution. Under the envisioned corporate structure, only the global parent goes into resolution, whereas all key operating entities continue to operate as usual, shielded from the resolution process. For example, under JPMorgan Chase's resolution plan, key operating entities are held by a bankruptcy-remote U.S. intermediate holding company (IHC) that holds all nonprepositioned capital and liquidity to support affiliates as going concerns in the event of an SPOE resolution of the parent company. Because it is bankruptcy remote, this IHC is shielded from the resolution process (and, in particular, from claims of long-term TLAC creditors of the parent) via a trust structure. ${ }^{28}$ However, although this structure indeed requires minimal action from foreign regulators, it does not prevent ring-fencing when foreign regulators determine that the resolution involves transfers that are not in their (national) interests. In fact, in its resolution plan, JPMorgan Chase (2017) acknowledges that "[a]lthough we have made these preparations, as a conservative measure, our resolution plan assumes soft ring-fencing, which is where foreign regulators limit transfers of assets between affiliates [in] resolution."

Therefore, ensuring incentive compatibility requires additional measures. Two such measures are discussed in the current policy proposals. First, under the FSB proposal, minimum TLAC requirements are not imposed on a consolidated basis on a whole banking group, but rather on "each resolution entity within each G-SIB” (Financial Stability Board 2015, p. 9). Moreover, what counts as a resolution entity is flexible. ${ }^{29}$ At least in principle, this flexibility allows regulators to set resolution-entity boundaries such that cross-jurisdictional transfers do not violate ex post incentive compatibility constraints.

Second, within resolution areas, both the FSB and the Federal Reserve envision that incentive compatibility could be ensured through "prepositioned resources," essentially TLAC and liquidity that is preassigned to an affiliate in a particular jurisdiction. For example, the Federal Reserve's rules require U.S.based intermediate holding companies of foreign G-SIBs to hold minimum amounts of "internal TLAC" in the form of convertible long-term debt that is issued to the foreign parent. The idea is that if the intermediate holding company (or the regulator) holds the trigger for conversion, losses in the intermediate

28 The resolution plan of JPMorgan Chase (2017) states: "We designed our resolution strategy to minimize or eliminate the need for global regulatory cooperation by having only our parent company enter resolution proceedings in the United States, while our Key Operating Entities receive necessary capital and liquidity support and continue as going concerns under a trust insulated from the resolution process. This means that the only necessary actions by foreign regulators generally are processing of or approving the indirect change in control to the trust."

29 "A resolution entity may be a parent company, an intermediate or ultimate holding company, or an operating subsidiary. A G-SIB may have one or more resolution entities," Financial Stability Board (2015, p. 9). Note that, in contrast to the Fed proposal, the FSB proposal does not require the resolution entity to be a holding company. 
holding company can be pushed up unilaterally to the foreign parent holding company. ${ }^{30}$ This is effectively a preallocation of loss-absorbing capital, so as to limit ex post transfers and ensure incentive compatibility.

Broadly speaking, the constrained-efficient resolution regime characterized in Section 4.4 supports the view that loss-absorbing capital may have to be preassigned to jurisdictions. However, as shown in Proposition 6, preallocation of TLAC must go hand in hand with a reduction in the required crossjurisdictional transfers during resolution. The issue is that the diversifiable cash flow $\Delta$ cannot be pre-assigned to a jurisdiction and therefore can be ringfenced even in the presence of internal TLAC. In addition to prepositioning capital, making transfers incentive compatible therefore requires limiting shortterm debt in each affiliate. Moreover, intermediate holding companies in each jurisdiction could issue external TLAC (i.e., long-term securities issued to outside investors rather than the parent holding company), such that some losses are absorbed by outside investors and not passed up to the global holding company, thereby limiting required transfers.

Interestingly, while our analysis suggests that it is efficient to set preassigned TLAC requirements to just satisfy ex post incentive compatibility (thereby maximizing the diversification benefits from shared loss-absorbing capacity subject to incentive compatibility), the internal TLAC rules proposed by the Federal Reserve seem to go significantly beyond what is required for incentive compatibility: Out of the $21 \%$ TLAC requirement at the global holding company level, the proposed rules require that foreign G-SIBs with large affiliates in the U.S. preposition as much as $18 \%$ as internal TLAC for the U.S. affiliate in an intermediate holding company based in the United States. By prepositioning almost all loss-absorbing capital, this requirement significantly limits the sharing of loss-absorption capacity across jurisdictions, thereby diminishing one of the key advantages of a global SPOE resolution. From the perspective of a non-U.S. G-SIB, the resultant resolution framework then looks essentially like MPOE.

\subsection{TLAC composition}

Our model also sheds light on the debate about TLAC composition. In particular, our results highlight two advantages of having some TLAC in the form of debt rather than equity. First, in our analysis of privately optimal TLAC composition we show that, up to a certain amount, banks have a preference for issuing TLAC in the form of long-term debt rather than equity because this reduces the asymmetric information discount on TLAC securities. Insisting on all-equity TLAC may therefore affect the bank's participation constraint: Because of the asymmetric information discount, the bank may decide not to operate or, in a model with variable scale, operate at an inefficient scale. Second, our analysis

30 Losses are not automatically passed up if the global parent holds the trigger for conversion, because it may simply decide to walk away rather than absorb the losses. 
of incentives establishes that TLAC in the form of long-term debt can have desirable incentive effects. However, recall that the incentive effects of the TLAC composition differ across SPOE and MPOE resolution. Under SPOE, long-term debt always improves incentives, but this is not the case under MPOE, where equity can be incentive maximizing. Interestingly, these justifications for TLAC in the form of debt rather than equity differ from those put forward by the Fed. ${ }^{31}$

\subsection{Resolution areas}

Our model can be extended to resolution areas consisting of more than two jurisdictions. Following the same logic as used in the analysis above, we can rewrite both the ex ante and ex post incentive constraints for SPOE resolution with $N$ jurisdictions. Specifically, assume that jurisdiction $i$ receives $\Delta$ with probability $\theta_{i}$, where $\sum_{i=1}^{N} \theta_{i}=1$. Under SPOE, the jurisdiction that receives $\Delta$ then makes a transfer of $\Delta / N$ to each of the $N-1$ remaining jurisdictions. The net expected transfer made by jurisdiction $i$ under SPOE is therefore given by $\left(1-p_{1}\right)\left(\theta_{i}-\frac{1}{N}\right) \Delta$. This transfer will be weighed against the benefit of joining the $N$-country resolution area, which is given by $\frac{\Delta}{N} \gamma+\min \left[\widetilde{F}-F,\left(1-p_{1}+\right.\right.$ $\left.\gamma)\left(1-\lambda_{N}\right) \bar{p}_{2} V\right]$. The ex ante IC constraint for the $N$-jurisdiction resolution area is therefore

$$
\max \left[\theta_{i}\right] \leq\left(1+\frac{\gamma}{1-p_{1}}\right) \frac{1}{N}+\frac{1}{\Delta} \min \left[\frac{\widetilde{F}-F}{1-p_{1}},\left(1+\frac{\gamma}{1-p_{1}}\right)\left(1-\lambda_{N}\right) \bar{p}_{2} V\right]
$$

where $\lambda_{N}$ captures the loss of value when the subsidiary in jurisdiction $i$ is separated from the remaining $N-1$ subsidiaries. Extending (4) to the $N$ country setting, the ex post IC constraint for the $N$-country resolution area is given by

$$
\frac{N-1}{N} \Delta \leq\left(1-\lambda_{N}\right) \bar{p}_{2} V
$$

The $N$-country IC constraints (15) and (16) show that the main difference from the two-jurisdiction case is that incentive compatibility of SPOE resolution requires larger cross-country complementarities $\lambda_{N}$ to be incentive compatible. From an ex ante perspective, this is the case because the per-jurisdiction risksharing benefit is decreasing in the number of jurisdictions, such that larger scale-economy benefits are required for incentive compatibility. From an ex post perspective, larger complementarities are required because the realized transfer that needs to be supported is larger $\left(\frac{N-1}{N} \Delta\right.$ instead of $\left.\Delta / 2\right)$. Larger

31 In the Fed's view, the objective of the long-term debt requirement is to ensure that loss-absorption capacity is not already used up (by depleting equity) before resolution is triggered. Under the Fed's "capital refill" framework, the long-term debt requirement is therefore set high enough to absorb losses and recapitalize the bank. See Federal Reserve (2015, pp. 26-27). 
resolution areas are therefore harder to sustain, both from an ex post and an ex ante perspective. Moreover, like in the two-jurisdiction case, asymmetries in the probability of receiving $\Delta$ hamper ex ante incentive compatibility, whereas larger required transfers make the ex post IC constraint harder to satisfy. $^{32}$

\subsection{The legal structure of foreign affiliates: Branches or subsidiaries?}

A number of papers have explored the choice between establishing foreign branches or subsidiaries. Our analysis adds an additional angle to this question. When it comes to bank resolution, the novel consideration is whether a branch structure can potentially relax the regulators' incentive compatibility constraints. Under a branch structure, all of the bank's assets are, at least in principle, located in one jurisdiction: the home jurisdiction. This can potentially eliminate the possibility of ring-fencing.

However, two important caveats arise. The first is that the possibility of ringfencing is only eliminated in cases where the "unity and universality principle" of bankruptcy applies. This principle is not universally applied in practice. Most prominently, instead of following the universality principle, U.S. bank insolvency law is territorial for a U.S. branch of a foreign bank, allowing U.S. authorities to ring-fence the foreign entity even though the U.S. operations of the foreign bank form a branch. Thus, a branch structure by itself does not necessarily eliminate the possibility of ring-fencing.

The second caveat is that, even if a branch structure can in principle protect against ring-fencing, it is not clear that G-SIBs could freely adopt such a structure if they wanted to. The reason is that both home and host regulators may prefer a subsidiary structure. As pointed out by Cerutti, Dell'Ariccia, and Martinez Peria (2007), both home and host regulators put restrictions on foreign branches.

Host regulators are particularly worried that, under a branch structure, they cede supervision to the home regulator. It is therefore likely that the host regulator will not allow the operation to be organized as a branch or, alternatively, the host regulator may severely restrict the activities that can be performed in branches (e.g., exclusion from mortgage business). Home regulators, on the other hand, worry that foreign branches are hard to supervise, and therefore they may also prefer foreign operations to be performed in subsidiaries, shifting the regulatory responsibility to the (perhaps better informed) host regulator. These considerations are particularly important for large, potentially systemic banks. In fact, Cerutti, Dell'Ariccia, and Martinez Peria (2007)

32 In the payoff specification above, the total risk-sharing benefit of the resolution area is fixed, leading to a lower per-jurisdiction benefit as $N$ grows, so that incentive compatibility then requires larger complementarities. If the risk-sharing benefit is increasing in the number of participating jurisdictions, this can help sustain larger resolution areas. 
document that large banks are less likely to organize their foreign operations as branches. ${ }^{33}$

\section{Conclusion}

This paper studies the resolution of global systemically important banks (GSIBs). Credible G-SIB resolution is a key component to ending too-big-to-fail, and regulators around the world have been working on proposals regarding the appropriate design of such resolution regimes. We contribute to this discussion by providing a formal economic analysis of the trade-offs that arise when choosing between different resolution models.

Our analysis highlights a key challenge in designing successful resolution regimes: The banks in question are global, whereas the regulators charged with carrying out the resolution are national. This tension necessitates careful consideration of the incentives of national regulators, both before and during resolution. Broadly speaking, our findings support the view that "[a]n effective resolution plan is not one-size-fits-all and is not designed in a vacuum. It must be tailored to the structure and business activities of a firm [...]" (JPMorgan Chase 2017). Our model emphasizes that successful bank resolution regimes need to consider the risk profile of a bank's cash flows and the operational complementarities across banking units located in different jurisdictions. Bank resolution must reflect the structure of global banks.

\section{Appendix A. The Need for Minimum TLAC}

This appendix contains the detailed derivation of the financing equilibrium under asymmetric information presented in Section 2, in particular Proposition 1. Because the result in Proposition 1 does not depend on the presence of multiple operating subsidiaries in different jurisdictions, we focus the analysis on one operating subsidiary in isolation (and therefore abstract from complementarities across jurisdictions and redundant systems).

Consider the financing choices of the owners of a single operating subsidiary. At date 0 , the setup cost $F$ can be funded via a combination of (1) short-term debt of face value $R_{1}$ due at date 1; (2) long-term subordinated debt with face value $R_{L T}$ due at date 2; and (3) an equity stake $\alpha_{0}$ issued to outside investors at date 0 . In addition, at date 1 the operating subsidiary can issue further claims against date 2 cash flows in order to roll over its (senior) short-term debt.

Financing choices are made by the informed owners of the operating subsidiary in a pooling equilibrium, like in Bolton and Freixas (2000, 2006). In this pooling equilibrium, the high type $\left(p_{2}^{i}=1\right)$ makes financing choices taking into account that it will be mimicked by the low type $\left(p_{2}^{i}=0\right)$. The high type will therefore seek to avoid issuing claims against the continuation value $V$, which are sold at a discount in the pooling equilibrium. From the perspective of a high-type

33 The practical difficulty of moving to a branch structure, even when the regulators involved are well aligned, is illustrated by Nordea's change in legal structure. Nordea was able to eventually convert its Nordic banking subsidiaries, Nordea Bank Danmark A/S, Nordea Bank Finland Plc, and Nordea Bank Norge ASA, from Danish, Finnish, and Norwegian subsidiary banks to branches of the Swedish parent company, Nordea Bank AB (publ), but only after a decade-long struggle. Lastra and Wihlborg (2007) point out that, as of 2007, "Nordea's efforts have stalled, however, as a result of resistance from authorities in all the four countries involved [...]." 
subsidiary, the true value of a unit claim on $V$ is 1 , but uninformed investors are willing to pay only $\bar{p}_{2}<1$ for this claim. ${ }^{34}$

The underpricing of claims issued against the continuation value $V$ (from the perspective of the high type) entails a pecking order in funding sources, by which the issuer strictly prefers to first sell short-term claims on date 1 cash flows before considering issuing long-term claims. Up to the face value $C_{1}^{L}$, such short-term debt can always be repaid from the date 1 cash flows and can therefore be issued without incurring any informational dilution costs. Up to the face value $C_{1}^{L}+\bar{p}_{2} V$, the optimal strategy for the high-type issuer is to issue short-term debt at date 0 and only issue claims against the continuation value $V$ at date 1 in the event that the realized date 1 cash flow is smaller than the promised face value of the short-term debt. Such state-contingent issuance against $V$ is optimal because it minimizes dilution costs.

Taking into account the convenience yield of safe short-term debt $\gamma$, the owners of the operating subsidiary can therefore raise up to $(1+\gamma)\left(C_{1}^{L}+\bar{p}_{2} V\right)$ without incurring any default risk at date 1 . From a bank resolution perspective, the interesting case is therefore $F>(1+\gamma)\left(C_{1}^{L}+\bar{p}_{2} V\right)$ because, in this case, financing entirely by short-term debt exposes the banking subsidiary to default risk at the interim date. In what follows, we therefore focus on this case.

Assumption 1. Financing exclusively with short-term debt exposes the operating subsidiary to default risk. This requires that $F>(1+\gamma)\left(C_{1}^{L}+\bar{p}_{2} V\right)$.

When $F>(1+\gamma)\left(C_{1}^{L}+\bar{p}_{2} V\right)$, two relevant funding structures need to be compared: one where default is avoided at date 1 and one where it is not. To avoid default at date 1 , the operating subsidiary must issue no more than $R_{1}=C_{1}^{L}+\bar{p}_{2} V$ in short-term debt, the maximum amount of short-term debt that can be always be repaid or rolled over at 1 , after wiping out long-term claims in a resolution, if necessary. The remaining funds must be raised through a combination of subordinated long-term debt and equity, which absorb losses during a resolution. Alternatively, the operating subsidiary may raise the entire amount $F$ via short-term debt, without any long-term subordinated debt or equity issued by the holding company. Under this latter funding structure, the bank is exposed to default risk because, in the low-cash-flow state, it will be unable to roll over its short-term debt at date 1 (absent loss-absorbing capital, a resolution is not possible). In this case, short-term creditors run on the bank and liquidate its assets for an amount $L$. Liquidation is inefficient because it yields less than the expected cash flows from continuing the banking franchise, $L<\bar{p}_{2} V$.

We first consider the funding structure in which the holding company issues sufficient TLAC to ensure safety of the short-term debt issued by the subsidiary. The composition of this TLAC is such that, up to a face value of long-term subordinated debt of $\hat{R}_{L T} \equiv C_{1}^{H}+\Delta-R_{1}$, the holding company has a preference for issuing long-term debt rather than equity. This is because it is in the bank's interest to ensure that all cash that may be carried forward within the firm from date 1 to date 2 is pledged to investors, as this ensures that all fairly priced cash flows are completely sold to investors. ${ }^{35}$ Once all fairly priced cash flows have been sold, the owners are indifferent between any combination of outside equity issuance $\alpha_{0}$ and additional subordinated long-term debt $R_{L T} \geq \hat{R}_{L T}$ as loss-absorbing capital. Intuitively, once all fairly priced cash flows have been sold, the total asymmetric information discount associated with long-term securities does not depend on the mix between long-term debt and equity. Without loss of generality, we can therefore calculate the payoff to equityholders, assuming that all external loss-absorbing capital is in the form of

34 Like in Bolton and Freixas (2000, 2006), separating equilibria do not exist because banks with low continuation values can always costlessly mimic high types.

35 To see this, note that, in the high state, an operating subsidiary that also receives the cash flow $\Delta$ carries forward $C_{1}^{H}+\Delta-R_{1}$ in cash to date 2 . To make sure that all the fairly priced cash flows are sold, it is therefore optimal to issue at least this amount in long-term debt. Of course, this long-term debt is exposed to the asymmetric information friction in states in which the firm does not carry forward sufficient cash, but it is less informationally sensitive than equity because it maximizes the fraction of fairly priced cash flows that back the security. 
long-term subordinated debt. To reduce the number of cases, we also assume that $F$ is sufficiently large such that, in order to raise $F$, the bank issues at least $\hat{R}_{L T}$ in long-term debt. ${ }^{36}$

Maximum issuance of safe short-term debt $R_{1}=C_{1}^{L}+\bar{p}_{2} V$ raises $(1+\gamma)\left(C_{1}^{L}+\bar{p}_{2} V\right)$ in funds at date 0 . The remaining amount $F-(1+\gamma)\left(C_{1}^{L}+\bar{p}_{2} V\right)$ is then raised via long-term subordinated debt, as explained above. The face value of long-term subordinated debt $R_{L T}$ must then satisfy

$$
\underbrace{p_{1} \bar{p}_{2} R_{L T}}_{\begin{array}{c}
R_{L T} \text { repaid when } \\
C_{1}=C_{1}^{H} \text { and } C_{2}=V
\end{array}}+\underbrace{p_{1}\left(1-\bar{p}_{2}\right)\left(C_{1}^{H}+\theta \Delta-R_{1}\right)}_{\begin{array}{c}
R_{L T} \text { partially repaid when } \\
C_{1}=C_{1}^{H} \text { and } C_{2}=0
\end{array}}+\underbrace{\left(1-p_{1}\right) \theta \Delta}_{\begin{array}{c}
\text { LT debt payoff } \\
\text { when } C_{1}=C_{1}^{L}
\end{array}}=F-\underbrace{(1+\gamma)\left(C_{1}^{L}+\bar{p}_{2} V\right)}_{\text {Funds raised with safe ST debt }} .
$$

The first term in this break-even condition reflects the fact that $R_{L T}$ is paid back in full at date 1 when the high cash flow $C_{1}^{H}$ is realized and the operating subsidiary has a positive continuation value $V$, which occurs with probability $p_{1} \bar{p}_{2}$ (from the perspective of uninformed investors). The second term captures the payoff when $C_{1}=C_{1}^{H}$ and $C_{2}=0$. In this case, available resources are not sufficient to repay both short-term and long-term creditors. Therefore, long-term creditors, who are structurally subordinated, receive whatever is left after short-term creditors have been paid their claim of $R_{1}=C_{1}^{L}+\bar{p}_{2} V$. The third term captures the payoff when $C_{1}=C_{1}^{L}$. The bank is resolved and long-term creditors receive an expected payoff of $\theta \Delta$, which is what is left after short-term creditors have been fully repaid. Based on this break-even condition, the face value of long-term subordinated debt is given by

$$
R_{L T}=\frac{F-(1+\gamma)\left(C_{1}^{L}-\bar{p}_{2} V\right)-p_{1}\left(1-\bar{p}_{2}\right)\left(C_{1}^{H}+\theta \Delta-C_{1}^{L}-\bar{p}_{2} V\right)-\left(1-p_{1}\right) \theta \Delta}{p_{1} \bar{p}_{2}},
$$

and the payoff to the owners of the high-type operating subsidiary is

$$
\begin{aligned}
\Pi_{T L A C} & =p_{1}\left[C_{1}^{H}+\theta \Delta+V-R_{1}-R_{L T}\right] \\
& =\frac{1}{\bar{p}_{2}}\left[p_{1} C_{1}^{H}+\left(1-p_{1}\right) C_{1}^{L}+\theta \Delta+\bar{p}_{2} V+\gamma\left(C_{1}^{L}+\bar{p}_{2} V\right)-F\right] .
\end{aligned}
$$

The expression in the first line of Equation (A3) captures that, under the maintained parameter assumptions, inside equityholders receive a payoff only if the high date 1 cash flow $C_{1}^{H}$ is realized, in which case their expected payoff is $C_{1}^{H}+\theta \Delta+V-R_{1}-R_{L T}$. The second line substitutes for $R_{1}$ and $R_{L T}$. The key observation here is that $d \Pi_{T L A C} / d \bar{p}_{2}$ is positive whenever having sufficient loss-absorbing capital requires issuing claims against the continuation value $V$ (this is the case when $\left.F>p_{1} C_{1}^{H}+\left(1-p_{1}\right) C_{1}^{L}+\gamma C_{1}^{L}+\theta \Delta\right)$. The expected profits to the owners of a high-type banking operation are lower when $\bar{p}_{2}$ is low because claims against $V$ are sold at a larger discount.

We now consider the second funding structure, under which the entire setup cost $F$ is funded with short-term debt. In this case, the operating subsidiary defaults whenever the low cash flow $C_{1}^{L}$ is realized, regardless of the realization of $\Delta$, provided that $\Delta$ is not too large. We will focus on this case, but the alternate case (where receiving $C_{1}^{L}+\Delta$ allows the operating subsidiary to service its short-term debt) can be treated in similar fashion.

Assumption 2. If exclusively financing with short-term debt, the operating subsidiary defaults whenever $C_{1}^{L}$ is realized, regardless of whether the additional cash flow $\Delta$ is received. This requires that $R_{1}>C_{1}^{L}+\Delta+\bar{p}_{2} V$, which holds as long as $\Delta$ is not too large.

36 This assumption implies that long-term debtholders are only repaid fully when $C_{1}=C_{1}^{H}$ and $C_{2}=V$. Relaxing this assumption would mean that long-term debtholders would also be fully repaid when $C_{1}=C_{1}^{H}$ and $C_{2}=0$. The expression for the face value of long-term debt would then be slightly different from the one calculated below, but none of the results would be affected. 
When the entire amount $F$ is raised by issuing short-term debt, short-term debt is risky and therefore does not generate the liquidity benefit $\gamma .{ }^{37}$ The face value of short-term debt then has to satisfy the break-even condition

$$
p_{1} R_{1}+\left(1-p_{1}\right)\left(C_{1}^{L}+\theta \Delta+L\right)=F .
$$

This break-even condition captures that short-term creditors are repaid in full when the high cash flow occurs. If the low cash flow is realized, creditors seize the available cash flow and liquidate the firm for a total expected payoff of $C_{1}^{L}+\theta \Delta+L$. This break-even condition yields a face value of short-term debt of

$$
R_{1}=\frac{F-\left(1-p_{1}\right)\left(C_{1}^{L}+\theta \Delta+L\right)}{p_{1}} .
$$

When exclusively financing in the form of short-term debt, under Assumption 2 the owners of the operating subsidiary receive a payoff only when the high cash flow is realized, in which case they receive cash flows $C_{1}^{H}+\theta \Delta+V$ net of the face value of short-term debt $R_{1}$. The expected profit of a high-type operating subsidiary is then given by

$$
\begin{aligned}
\Pi_{\text {noTLAC }} & =p_{1}\left[C_{1}^{H}+\theta \Delta-R_{1}+V\right] \\
& =p_{1} C_{1}^{H}+\left(1-p_{1}\right) C_{1}^{L}+\theta \Delta+p_{1} V-\left(1-p_{1}\right) L-F,
\end{aligned}
$$

where the second line substitutes for $R_{1}$.

Comparing expected profits with and without sufficient loss-absorbing capital (Equations (A3) and (A6)) reveals that private incentives may be such that the owners of the banking operation do not issue securities that provide sufficient TLAC and instead exclusively rely on short-term debt. To see this, note first that financing with sufficient TLAC is privately optimal when claims against long-term cash flows are fairly priced $\left(\bar{p}_{2}=1\right)$. In this case, TLAC does not involve any dilution costs and generates a social benefit of safe short-term debt of $\gamma\left(C_{1}^{L}+\bar{p}_{2} V\right)$, which, in equilibrium, is appropriated by the bank. Risky debt financing, on the other hand, is costly because it does not generate a convenience yield and it leads to inefficient liquidation in the low cash-flow state. In contrast, when dilution costs on long-term cash flows are sufficiently high (when $\bar{p}_{2}$ lies below a cutoff $\bar{p}_{2}^{*}<1$ ), risky debt financing is privately optimal, even though it leads to inefficient early liquidation and eliminates the social benefit of short-term debt.

To derive the cutoff $\bar{p}_{2}^{*}$ below which short-term financing becomes optimal, we first note that $d \Pi_{T L A C} / d \bar{p}_{2}>0$ whenever sufficient loss-absorbing capital requires issuing claims against the continuation value $V$ (i.e., when $\left.F>p_{1} C_{1}^{H}+\left(1-p_{1}\right) C_{1}^{L}+\gamma C_{1}^{L}+\theta \Delta\right)$. This can be seen from

$$
\frac{d \Pi_{T L A C}}{d \bar{p}_{2}}=\frac{F-p_{1} C_{1}^{H}-\left(1-p_{1}\right) C_{1}^{L}-\gamma C_{1}^{L}-\theta \Delta}{\left(\bar{p}_{2}\right)^{2}} .
$$

Next, solving $\Pi_{T L A C}=\Pi_{n o T L A C}$ for $\bar{p}_{2}$ yields the unique cutoff

$$
\bar{p}_{2}^{*}(\gamma, L)=\frac{F-p_{1} C_{1}^{H}-\left(1-p_{1}+\gamma\right) C_{1}^{L}-\theta \Delta}{F-p_{1} C_{1}^{H}-\left(1-p_{1}+\gamma\right) C_{1}^{L}-\theta \Delta+\left(1-p_{1}\right)(V-L)+\gamma\left(C_{1}^{L}+V\right)} .
$$

Given that $d \Pi_{T L A C} / d \bar{p}_{2}>0$, risky short-term debt financing is then chosen whenever $\bar{p}_{2}<$ $\bar{p}_{2}^{*}(\gamma, L)$, as stated in Proposition 1 . Therefore, SPOE and MPOE resolution schemes, both of which crucially rely on sufficient TLAC, must in general be complemented by a minimum TLAC requirement.

37 The entire liquidity benefit of short-term debt is lost when short-term debt risky. One could extend the model to allow for two types of short-term debt with different seniority (e.g., by collateralizing some of the short-term debt or issuing a covered bond), in which the safe senior short-term debt retains the liquidity benefit. The bank's decision to issue sufficient TLAC then purely depends on the trade-off between the asymmetric information discount of long-term securities and the cost of inefficient liquidation, and the bank would be less likely to issue sufficient TLAC. 


\section{Appendix B. Proofs}

Proof of Proposition 8: From the IC constraints (7) and (10), we find that, after canceling terms, the incentives for the manager of subsidiary $i$ to exert effort to produce $\Delta$ are better under SPOE resolution when

$$
\left(1-\alpha_{0}^{\mathrm{SPOE}}\right) p_{1}>\left(1-\alpha_{0, i}^{\mathrm{MPOE}}\right)\left[p_{1}+\left(1-p_{1}\right) \frac{p_{2}^{i}}{\bar{p}_{2}}\right]
$$

Part 1 of the proposition directly follows from (B1). To derive the sufficient condition given in part 2, we substitute (12) and (9) into (B1). Setting $\lambda=1$ and eliminating terms, we then obtain the condition

$$
\begin{array}{r}
{\left[(1+\gamma)\left(C_{1}^{L}+\bar{p}_{2} V\right)+p_{1}\left(C_{1}^{H}-C_{1}^{L}\right)+\frac{\Delta}{2}-F\right]\left[\left(1-p_{1}\right) p_{2}^{i}\left(C_{1}^{H}-C_{1}^{L}\right)-(1+\gamma) \bar{p}_{2} \frac{\Delta}{2}\right]} \\
<\gamma \bar{p}_{2} \frac{\Delta}{2}\left[F-(1+\gamma)\left(C_{1}^{L}+\bar{p}_{2} V\right)\right]
\end{array}
$$

A sufficient condition is therefore that $\Delta$ satisfies

$$
\underbrace{\left[(1+\gamma)\left(C_{1}^{L}+\bar{p}_{2} V\right)+p_{1}\left(C_{1}^{H}-C_{1}^{L}\right)+\frac{\Delta}{2}-F\right]}_{>0}\left[\left(1-p_{1}\right) p_{2}^{i}\left(C_{1}^{H}-C_{1}^{L}\right)-(1+\gamma) \bar{p}_{2} \frac{\Delta}{2}\right]<0,
$$

which holds when (14) is satisfied. Given that $\frac{d \alpha_{0, i}^{\mathrm{MPOE}}}{d \lambda}<0$ and $\frac{d \alpha_{0}^{\mathrm{SPOE}}}{d \lambda}=0$, this condition is sufficient but not necessary. Part 3 follows from the observation that asymmetry $\left(\theta_{1} \neq \theta_{2}\right)$ reduces the inside equity stake of the subsidiary for which $\theta_{i}<1 / 2$, thereby reducing incentives to produce $\Delta$ for this subsidiary under MPOE, while incentives under SPOE are not affected.

\section{References}

Anderson, R. W., and K. Jõeveer. 2017. Bankers and bank investors: Understanding the performance of large, complex banks. Working Paper, London School of Economics.

Bebchuk, L. A., and A. T. Guzman. 1999. An economic analysis of transnational bankruptcies. Journal of Law and Economics 42:775-808.

Beck, T., R. Todorov, and W. Wagner. 2013. Supervising cross-border banks: Theory, evidence and policy. Economic Policy 73:5-44.

Beck, T., and W. Wagner. 2016. Supranational supervision: How much and for whom? International Journal of Central Banking 12:221-68.

Berger, A. N., W. C. Hunter, and S. G. Timme. 1993. The efficiency of financial institutions: A review and preview of research past, present and future. Journal of Banking \& Finance 17:221-49.

Bolton, P., and X. Freixas. 2000. Equity, bonds, and bank debt: Capital structure and financial market equilibrium under asymmetric information. Journal of Political Economy 108:324-51.

- 2006. Corporate finance and the monetary transmission mechanism. Review of Financial Studies 19:829-70.

Calomiris, C. W., and C. M. Kahn. 1991. The role of demandable debt in structuring optimal banking arrangements. American Economic Review 81:497-513.

Calzolari, G., J.-E. Colliard, and G. Lóránth. Forthcoming. Multinational banks and supranational supervision. Review of Financial Studies. 
Calzolari, G., and G. Lóránth. 2011. Regulation of multinational banks: A theoretical inquiry. Journal of Financial Intermediation 20:178-98.

Carletti, E., G. Dell'Ariccia, and R. Marquez. 2015. Supervisory incentives in a banking union. Working Paper, Bocconi, IMF, and UC Davis.

Cerutti, E., G. Dell'Ariccia, and M. S. Martinez Peria. 2007. How banks go abroad: Branches or subsidiaries? Journal of Banking \& Finance 31:1669-92.

Colliard, J.-E. 2017. Optimal supervisory architecture and financial integration in a banking union. Working Paper, HEC.

Colliard, J.-E., and D. Gromb. 2018. Financial restructuring and resolution of banks. Working Paper, HEC.

Dell'Ariccia, G., and R. Marquez. 2006. Competition among regulators and credit market integration. Journal of Financial Economics 79:401-30.

Diamond, D. W., and P. H. Dybvig. 1983. Bank runs, deposit insurance, and liquidity. Journal of Political Economy 91:401-19.

Diamond, D. W., and A. K. Kashyap. 2016. Liquidity requirements, liquidity choice and financial stability. In Handbook of macroeconomics, vol. 2B, eds. J. B. Taylor and H. Uhlig, 2263-303. Amsterdam: North Holland.

Diamond, D. W., and R. G. Rajan. 2001. Liquidity risk, liquidity creation, and financial fragility: A theory of banking. Journal of Political Economy 109:287-327.

Donaldson, J. R., and G. Piacentino. 2018. Money runs. Working Paper, Washington University at St. Louis and Columbia University.

Duffie, D. 2014. Resolution of failing central counterparties. In Making failure feasible: How bankruptcy reform can end "too big to fail", eds. K. E. Scott, T. H. Jackson, and J. B. Taylor, 87-109. Stanford, CA: Hoover Institution.

Ervin, D. W. 2017. The risky business of ring-fencing. Working Paper.

Faia, E., and B. Weder di Mauro. 2016. Cross-border resolution of global banks: Bail in under single point of entry versus multiple points of entry. Working Paper, Goethe University Frankfurt and University of Mainz.

FDIC and Bank of England. 2012. Resolving globally active, systemically important, financial institutions. Report.

Federal Reserve. 2015. Total loss-absorbing capacity, long-term debt, and clean holding company requirements for systemically important U.S. bank holding companies and intermediate holding companies of systemically important foreign banking organizations. 12 CFR Parts 217 and 252.

Financial Stability Board. 2013. Recovery and resolution planning for systemically important financial institutions: guidance on developing effective resolution strategies. Report.

2014. Key attributes of effective resolution regimes for financial institutions. Report.

2015. Principles on loss-absorbing and recapitalisation capacity of G-SIBs in resolution: Total lossabsorbing capacity (TLAC) term sheet. Report.

Flannery, M. J. 2014. Contingent capital instruments for large financial institutions: A review of the literature. Annual Review of Financial Economics 6:225-40.

Greenwood, R., S. G. Hanson, and J. C. Stein. 2015. A comparative-advantage approach to government debt maturity. Journal of Finance 70:1683-722.

HSBC. 2015. Annual report and accounts.

Hughes, J. P., and L. J. Mester. 2013. Who said large banks don't experience scale economies? Evidence from a risk-return-driven cost function. Journal of Financial Intermediation 22:559-85.

Jackson, T. H., and D. A. Skeel. 2012. Dynamic resolution of large financial institutions. Harvard Business Law Review 2:435-60. 
Jensen, M. C., and W. H. Meckling. 1976. Theory of the firm: Managerial behavior, agency costs and ownership structure. Journal of Financial Economics 3:305-60.

JPMorgan Chase. 2017. Resolution plan public filing. Report.

Klein, B. 1974. Competitive interest payments on bank deposits and the long-run demand for money. American Economic Review 64:931-49.

Krishnamurthy, A., and A. Vissing-Jorgensen. 2012. The aggregate demand for Treasury debt. Journal of Political Economy 120:233-67.

- 2015. The impact of Treasury supply on financial sector lending and stability. Journal of Financial Economics 118:571-600.

Lastra, R., and C. Wihlborg. 2007. Law and economics of crisis resolution in cross-border banking. In Prompt corrective action and cross-border supervisory issues in Europe, eds. H. Benking, C. Goodhart, and R. Lastra, 90-112. London: Financial Markets Group.

Li, Y. 2017. Procyclical finance: The money view. Working Paper, Ohio State University.

Lóránth, G., and A. Morrison. 2007. Deposit insurance, capital regulations, and financial contagion in multinational banks. Journal of Business Finance and Accounting 34:917-49.

Mendicino, C., K. Nikolov, and J. Suarez. 2018. Equity versus bail-in debt in banking: An agency perspective. Working Paper, ECB and CEMFI.

Nagel, S. 2016. The liquidity premium of near-money assets. Quarterly Journal of Economics 131:1927-71.

Philippon, T., and A. Salord. 2017. Bail-ins and bank resolution in Europe. Geneva Reports on the World Economy Special Report 4.

Schoenmaker, D. 2013. Governance of international banking: The financial trilemma. Oxford, UK: Oxford University Press.

Segura, A., and S. Vicente. 2018. Bank resolution and the public backstop in an asymmetric banking union. Working Paper, Bank of Italy and Universidad Carlos III de Madrid.

Skeel, D. A. 2014. Single point of entry and the bankruptcy alternative. In Across the great divide: New perspectives on the financial crisis, eds. M. N. Baily and J. B. Taylor, 311-33. Stanford, CA: Hoover Institution.

Sunderam, A. 2014. Money creation and the shadow banking system. Review of Financial Studies 28:939-77.

Tucker, P. 2013. Solving too big to fail-where do things stand on resolution? Speech at the Institute of International Finance, Washington DC, October 12, 2013.

. 2014a. Regulatory reform, stability, and central banking. Hutchins Center on Fiscal and Monetary Policy at Brookings. Report.

2014b. The resolution of financial institutions without taxpayer solvency support: Seven retrospective clarifications and elaborations. Comments given at the European Summer Symposium in Economic Theory, Gerzensee, Switzerland.

Walther, A., and L. White. 2017. Bail-ins and bail-outs in bank resolution. Working Paper, Boston University and Imperial College London.

Wheelock, D. C., and P. W. Wilson. 2012. Do large banks have lower costs? New estimates of returns to scale for U.S. banks. Journal of Money, Credit and Banking 44:171-99. 